\title{
Speak better, do better? Education and health of migrants in the $\mathrm{UK}^{*}$
}

\author{
Yu Aoki, ${ }^{a \dagger}$ Lualhati Santiago ${ }^{\mathrm{b}}$ \\ ${ }^{a}$ Department of Economics, University of Aberdeen, Dunbar Street, Aberdeen, AB24 3QY, United Kingdom \\ ${ }^{\mathrm{b}}$ Public Policy Division, Office for National Statistics, 1 Drummond Gate, Pimlico, London, SW1V 2QQ, United \\ Kingdom
}

\begin{abstract}
Does proficiency in host-country language affect immigrant social outcomes? This paper aims to address this question by estimating the causal effects of English language skills on education, health and fertility outcomes of immigrants in England and Wales. We construct an instrument for language skills using age at arrival in the United Kingdom, exploiting the phenomenon that young children learn languages more easily than older children. Using a unique individual-level dataset that links the 2011 Census data to life event records, we find that better English language skills significantly improve educational attainment and adult health, and affect fertility behaviour, but do not affect child health. Supplementary analysis suggests that a higher educational attainment as a result of better English language skills is a possibly important channel though which English proficiency affects immigrant health. Keywords: Immigration, language skills, education, health, fertility. JEL codes: I10, I21, J13, $\mathrm{J} 15$.
\end{abstract}

\section{Introduction}

The foreign-born share of the population increased in most countries in the Organisation for Economic Co-operation and Development (OECD) between 2000/01 and 2009/10 (OECD, 2012), and the social integration of immigrants is high on the policy agenda of developed countries. In order to implement successful policies to target social and health inequalities

\footnotetext{
*Acknowledgments: We are grateful to the editor, Albrecht Glitz, and two anonymous reviewers for comments that helped greatly improve our paper. We also gratefully acknowledge the permission of the Office for National Statistics (ONS) to use the Longitudinal Study, and the help provided by staff of the Centre for Longitudinal Study Information and User Support, which is supported by the ESRC Census of Population Programme (Award Ref: ES/K000365/1). We thank Richard Prothero, and the participants of the EALE/SOLE meeting in Montreal, ESPE conference in Izmir, Applied Economics workshop in Catanzaro, and seminars/workshops at the University of Aberdeen, University of Alicante and CPB Netherlands Bureau for Economic Policy Analysis for discussions that improved this paper. Financial support from the Scottish Institute for Research in Economics and the Carnegie Trust for the Universities of Scotland is also gratefully acknowledged. The authors alone are responsible for the interpretation of the data.

This work contains statistical data from the ONS which is Crown Copyright and all statistical results remain Crown Copyright. The use of the ONS Statistics statistical data in this work does not imply the endorsement of the ONS in relation to the interpretation or analysis of the statistical data. This work uses research datasets which may not exactly reproduce National Statistics aggregates.

${ }^{\dagger}$ Corresponding author.

E-mail addresses: y.aoki@abdn.ac.uk (Aoki), lualhati.santiago@ons.gov.uk (Santiago)
} 
among their immigrant population, policy makers need to understand what barriers immigrants face to integrate. Among possible barriers, this paper focuses on language. Language facilitates access and use of public services, such as those related to education and health, and this in turn may affect the educational achievement and health of immigrants. There is extensive evidence that better language skills improve immigrant economic status, in particular their earnings, but there is limited research on how language affects their social life and family structures (Chiswick and Miller, 2014). There is also limited knowledge on how language affects immigrant health outcomes and behaviour. This paper aims to contribute to this literature by estimating the causal effects of English language skills on a number of education, health and fertility outcomes for immigrants in England and Wales.

Our paper contributes to the literature on the effect of language skills on these social outcomes in a number of ways. First, we use a unique dataset from the Office for National Statistics (ONS) England and Wales Longitudinal Study, which links individual-level dataset from the 2011 Census for England and Wales and Live Births to Sample Mothers, which contains information on births to sample women in the longitudinal study. The combination of these two datasets allows us to study the impact of language skills on various fertility outcomes that, to the best of our knowledge, have not been studied before: a woman's age at having her first child, the number of biological children a woman has, and the birthweight of children. Second, we are first to provide evidence on how language skills affect health outcomes of immigrants in England and Wales. Research on the relation between language skills and health of immigrants in the United Kingdom (UK) is very limited because there are very few health datasets in the UK that incorporate information on English language skills (Jayaweera, 2014). Third, we provide an important contribution to the literature by presenting results from a country with a very different immigration composition to that of the United States (US), the country on which most studies in this literature are based. OECD (2012) indicates that the UK and the US have similar shares of immigrants - $11.3 \%$ of the total population in the UK, $12.5 \%$ in the US - but the two countries are different in a key characteristic of interest to our analysis: $47 \%$ of immigrants in the UK come from English-speaking countries, compared to $20 \%$ of immigrants in the US. In addition, $47 \%$ of immigrants in the UK are highly educated, compared to $34 \%$ among immigrants in the US, and $34 \%$ of immigrants in the UK come from OECD high-income countries, compared to only $14 \%$ of immigrants in the US. Lastly, this is the first paper that explicitly accounts for parental education, which is possibly an important omitted variable in the analysis of the causal effects of English language skills on education.

Credibly identifying and quantifying the impact of language proficiency on social outcomes pose a significant empirical challenge because English language proficiency is likely to be endogenous. First, unobserved individual characteristics that affect both English proficiency and these social outcomes, such as ability and cultural attitude, may bias estimates of the effect of English proficiency. Second, these social outcomes can also affect an individ- 
ual's English proficiency (reverse causality); for example, having children might improve a woman's English skills if this leads her to interact more frequently with English-speaking parents and schoolteachers. Third, measurement error in the measure of English proficiency can also cause a bias in the Ordinary Least Squares (OLS) estimator. To address this possible endogeneity problem, we use an instrumental variable (IV) strategy, where we exploit age at arrival in the UK to construct an instrument for English skills. Bleakley and Chin (2004) are first to exploit age at arrival to construct an IV for language skills of immigrants, based on the "critical period hypothesis" of language acquisition. This hypothesis, proposed by Lenneberg (1967), suggests that a person exposed to a language within the critical period of language acquisition (i.e., childhood) can learn it more easily, implying that nonEnglish-speaking immigrants who arrived in the UK when they were young children would have on average better English language skills than those who arrived when they were older.

However, age at arrival alone is not a valid instrument because it is likely to have direct effects on the immigrant social outcomes through channels different from language acquisition; for example, through cultural assimilation or better knowledge of institutions and social services. To address these concerns, we use immigrants from English-speaking countries as a control to partial out age-at-arrival effects that affect the immigrant social outcomes through channels different from language acquisition. More precisely, conditional on individual characteristics, any difference observed in the outcomes of early and late arrivers from English-speaking countries would reflect an age-at-arrival effect, while this same difference, for the case of immigrants from non-English-speaking countries, would reflect an age-at-arrival effect and an additional effect, namely, the language effect. Thus, the difference in outcomes between early and late arrivers from non-English-speaking countries in excess of its equivalent difference for those from English-speaking countries can arguably be attributed to the effect of language.

Furthermore, among immigrants born in non-English-speaking countries, there is variation in how close their native languages are to English, and those from a country with a native language closer to English (e.g., Dutch) would find it easier to learn English than immigrants whose mother tongue is more linguistically distant (e.g., Vietnamese). Following Clarke and Isphording (2017), we account for this heterogeneity in native languages of immigrants from non-English-speaking countries in our analysis, and construct an instrument for English language proficiency, which is an interaction of age at arrival with linguistic distance between the origin-country language and English.

Using this IV for English skills, we find a considerable impact on immigrant educational attainment: Better English skills significantly raise the likelihood of having an academic degree and a post-compulsory qualification, and reduce that of having a compulsory qualification or no qualifications as the highest level of qualification obtained. Our IV estimates also indicate the effects on health and fertility outcomes: Better proficiency in English significantly decreases the likelihood of teenage childbearing and improves self-reported adult 
health, but does not affect child health. Supplementary analysis suggests that an improved educational attainment as a result of better English skills is a possible important channel through which language skills affect self-reported adult health.

The remainder of the paper proceeds as follows. Section 2 reviews the literature on the effects of language skills on immigrant social outcomes. Section 3 presents our econometric specification, and discusses empirical problems and identification strategy. Section 4 describes our sample and data on education, health and fertility, while Section 5 discusses main empirical findings. Section 6 investigates the robustness of the main results to different sample and regression specifications. Finally, Section 7 discusses policy implications and concludes the paper.

\section{Literature review}

The literature that explores the causal effect of language skills on education, health and fertility outcomes is not extensive. The relation between language skills and education has been explored in a limited number of studies; for example, Glick and White (2003) analyse factors that may explain the academic performance of immigrants and find that having a non-English background is associated with lower test scores of immigrants in the US. The majority of studies that explore the educational attainment of immigrants do not focus directly on language proficiency, and instead study how age at arrival affects their ability to close the education gap with natives and second-generation immigrants (e.g., Böhlmark, 2008; Cortes, 2006). The conclusions drawn in some of these studies suggest that language proficiency could be a key factor explaining the educational attainment of immigrant children. For example, Corak (2011) finds a negative impact of age at arrival on holding a high school diploma for immigrant children who arrived in Canada after age nine, but only for those arriving from non-English- or non-French-speaking countries. Also, Cohen Goldner and Epstein (2014), using data from Israel, arrive to a similar conclusion: Age at arrival has a negative impact on the probability of graduating from high school, and they suggest that a possible channel for this may be language acquisition.

A challenge for studying the effect of language skills on education is that causation is difficult to establish because language skills are endogenous; for instance, better language skills help achieve better academic results, but studying for a higher level of education also helps improve one's language ability since it would require more reading and writing. To overcome the endogeneity of language skills, Bleakley and Chin (2004) and Akbulut-Yuksel et al. (2011) create an IV for language skills using an interaction between age at arrival in the US and an indicator for being born in a non-English-speaking country. Using this IV, their results indicate that better English skills increase the number of years of schooling, and the likelihood of having a high school diploma and of having an academic degree.

The role of language skills on health and fertility outcomes has been analysed by social 
scientists across different disciplines, including Sociology, Epidemiology and Behavioural Sciences. Most studies examine correlations between language skills and health or fertility outcomes. Regarding health outcomes, a number of papers analyse the role of language skills in the context of acculturation in the US. Their findings appear to be mixed: Bauer et al. (2012) and Lee et al. (2013) find insignificant correlations between English language proficiency and health outcomes, while Kimbro et al. (2012) and Miranda et al. (2011) find that this correlation is positive. An issue with these studies is that it is not clear if poor language skills deteriorate health due to, for example, a poor interaction with healthcare professionals, or if poor health hinders the development of language skills because, for example, it limits interactions with other people. Guven and Islam (2015) address this endogeneity of language skills by using IVs for language skills, which are an interaction of indicators for being born in a non-English speaking country and arriving young in Australia, and an interaction of indicators for English not being the first language spoken as a child and arriving young in Australia. Using these instruments in separate regression models, they find that better English skills improve self-reported health and physical health, although their results appear to be sensitive to sample specifications. Using the same Australian dataset as Guven and Islam (2015), Clarke and Isphording (2017) proceed a step further when constructing their IV for English skills: Namely, among non-native-speaking immigrants, they account for the heterogeneity in similarity between home-country language and English. Using an interaction of age at arrival with a continuous measure of linguistic distance between English and the home-country language as an IV for English deficiency, they find that English deficiency significantly deteriorates the physical health of immigrants.

A small number of studies investigate the relation between language skills and fertility. Focusing on individuals in the US with Hispanic origin, research finds that poor English proficiency is significantly associated with higher fertility rates (e.g., Lichter et al., 2012). In contrast, using Canadian data, Adsera and Ferrer (2014) find that the number of children that immigrants have increases with age at immigration relative to that of natives, regardless of language proficiency in the official languages in Canada (i.e., English and French). They find that the fertility rates of all immigrants, including those coming from English- or French-speaking countries, are higher than those of the native-born, suggesting that language proficiency is unlikely to play a key role in explaining a higher fertility among immigrants. A possible issue with these studies is that unobserved heterogeneity that affects the fertility decision of a woman, such as cultural attitude, may be correlated with her language proficiency. Reverse causality may also be an issue. Bleakley and Chin (2010) and Akbulut-Yuksel et al. (2011) address this potential endogeneity using an interaction between age at arrival and being born in a non-English-speaking country as an IV for language skills of immigrants in the US. Both studies suggest that English skills significantly reduce the number of children. A limitation is that both studies use the number of children living in same household as a measure of fertility, which is not necessarily the actual number of 
children a person has.

\section{Identification strategy}

We explore the causal effect of English language proficiency on education, health and fertility outcomes of immigrants living in England and Wales by regressing these outcomes on a measure of English language proficiency, controlling for various individual characteristics. We specify the following model:

$$
\text { outcome }_{i c a}=\beta_{0}+\beta_{1} \text { proficiency }_{i c a}+X_{i c a}^{\prime} \delta+\gamma_{c}+\eta_{a}+\varepsilon_{i c a}
$$

where outcome $e_{i c a}$ represents the outcome of individual $i$ born in country $c$ who arrived in the UK at age $a$, and proficiency ${ }_{i c a}$ is a measure of English language proficiency. ${ }^{1}$ The individual characteristics, $X_{i c a}$, and the parameter $\delta$ are $K \times 1$ vectors, where $K$ is the number of variables capturing individual characteristics such as age and gender. $\gamma_{c}$ and $\eta_{a}$ are country-of-birth and age-at-arrival fixed effects, respectively, and $\varepsilon_{i c a}$ is the disturbance term.

The main coefficient of interest is $\beta_{1}$, which measures the effect of English language proficiency on the outcomes that we analyse. An econometric issue in the estimation of equation (1) is the endogeneity of English proficiency. First, unobserved individual characteristics, such as cultural attitude, are likely to be correlated with both English proficiency and immigrant social outcomes. Second, social outcomes of an individual may affect the person's language proficiency (reverse causality). Third, there may be measurement error in our measure of language proficiency as it is self-reported. For these reasons, the OLS estimator for $\beta_{1}$ is unlikely to estimate the causal effect of English language skills.

To identify the causal effect, we use an IV strategy which requires an IV giving exogenous variation in English language skills. To construct an IV for language skills, we exploit age at arrival in the UK. The idea of using age at arrival in a host country to construct an IV was proposed by Bleakley and Chin (2004) and based on the "critical period of language acquisition" hypothesis suggested by Lenneberg (1967). According to this hypothesis, an individual exposed to a new language during the critical period of language acquisition (childhood) will be able to learn the language easily, while learning a new language after this critical period is more difficult. ${ }^{2}$ The critical period hypothesis implies that age

\footnotetext{
${ }^{1}$ Some outcomes we analyse are dummy variables. Although we could potentially specify non-linear models (e.g., probit model) for these outcomes, we use linear models for all outcomes for two main reasons. First, this allows us to be consistent in our model specification across regressions. Second, linear models have a more straightforward interpretation than non-linear models when working with instrumental variables. Angrist and Pischke (2009) argue that, although a non-linear model may fit the conditional expectation function for limited dependent variables more closely than a linear model, marginal effects computed from these two types of models are very similar.

${ }^{2}$ Lenneberg (1967) observes that, until early teens, individuals have an innate flexibility for the organisation
} 
at arrival in the UK would affect English language proficiency of immigrants arriving from countries where English is not spoken as a main language, because they had not been extensively exposed to English before arriving in the UK. More specifically, among immigrants born in non-English-speaking countries, those who arrive at an early age are likely to learn English more easily, while late arrivers would face more difficulties in learning English and may have a poorer command of the language. In contrast, age at arrival would not affect the proficiency in English of immigrants born in English-speaking countries, because they have been extensively exposed to English prior to their arrival in the UK.

For a variable to be a valid IV for English language skills, we require two assumptions: namely, it does not appear in equation (1), and it is not correlated with any other determinants of immigrant social outcomes except language skills. Age at arrival alone is unlikely to satisfy these assumptions because age at arrival affects not only language proficiency but also an individual's knowledge about UK institutions, which can subsequently affect his social outcomes. For example, early arrivers may have an advantage over late arrivers in attaining a higher level of education because they are more familiar with the UK educational systems. Likewise, early arrivers may have better health partly because they have a better knowledge of the UK healthcare systems.

To address these concerns, instead of using age at arrival as an IV, we could use an interaction of age at arrival with an indicator for coming from a non-English-speaking country. All immigrants are exposed to a new environment at arrival in the UK, but only those born in non-English-speaking countries encounter a new language. Thus, conditional on individual characteristics including country-of-birth fixed effects, any difference observed in the outcomes of early and late arrivers from English-speaking countries would reflect an age-at-arrival effect, while this same difference, for the case of immigrants from nonEnglish-speaking countries, would reflect an age-at-arrival effect and an additional effect, i.e., the language effect. Therefore, a difference in the outcomes between early and late arrivers born in non-English-speaking countries in excess of the corresponding difference for immigrants born in English-speaking countries can be arguably attributed to the effects of language.

Fig. 1 plots education, fertility and health outcomes by age at arrival: Namely, panels (a) to (d) plot likelihood of having no qualifications, that of having a child in her teens (women only), number of biological children (women only), and self-reported health ordinal measure, respectively. ${ }^{3}$ The dashed and solid lines correspond to immigrants born in Englishand non-English-speaking countries, respectively. ${ }^{4}$ Panels (a) and (b) show that, among

of brain functions necessary for the acquisition of a language. If basic language skills have not been acquired by puberty, they tend to remain deficient for the rest of their life because the ability to adjust to physiological demands for verbal acquisition declines sharply after puberty due to physiological changes in brain.

${ }^{3}$ As we have numerous outcome variables, we do not report graphs for every outcome for the sake of space. Instead, we report the relation between age at arrival and each education, health and fertility outcome (i.e., reduced-form estimates) in Table 2.

${ }^{4}$ Fig. 1 shows trends for late arrivers born in English-speaking countries. These trends imply that age at 


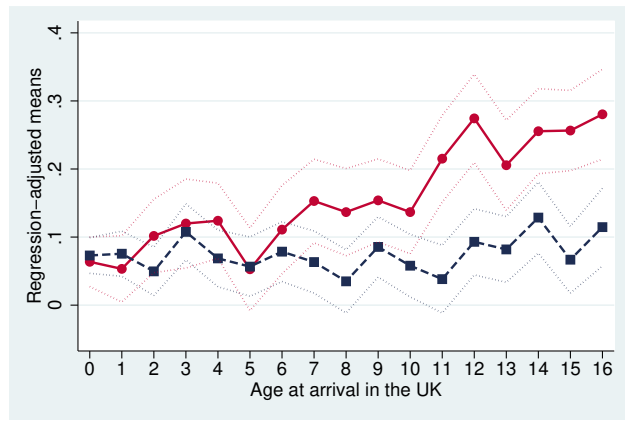

(a) No qualifications

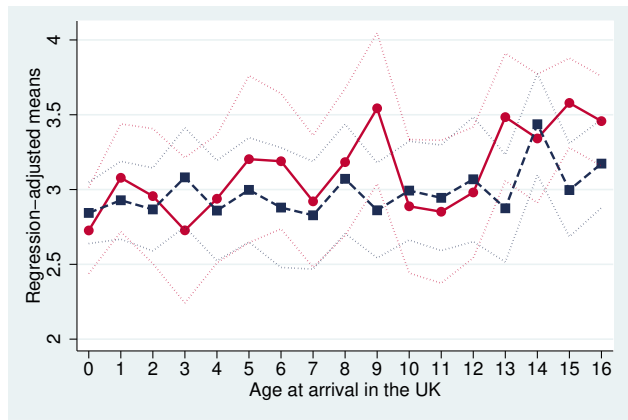

(c) Number of children

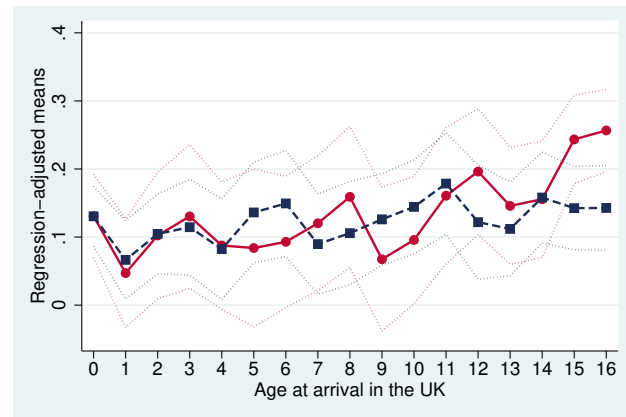

(b) Teenage mother

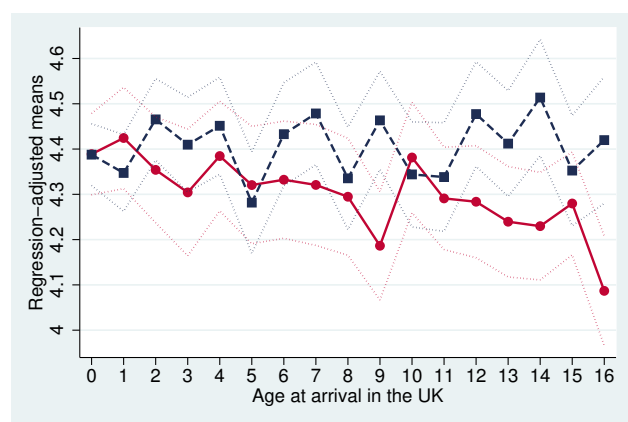

(d) Self-reported health (1 - 5)

English-speaking country of birth

Fig. 1. Education, fertility and health by age at arrival.

Notes: Panels (a) to (d) plot measures of education (likelihood of having no qualifications), fertility (likelihood of teenage childbearing; number of biological children) and health (self-reported health), respectively, by age at arrival. Two sets of outer lines correspond to $95 \%$ confident intervals. Every outcome is regression adjusted for age, sex and race.

Source: ONS Longitudinal Study. 


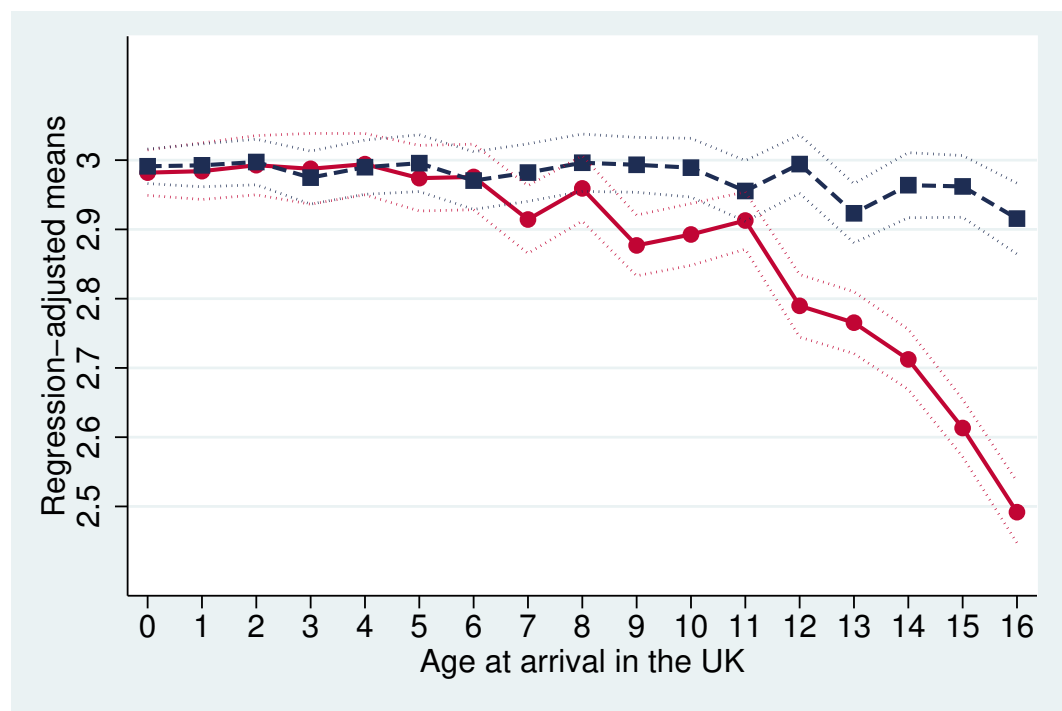

$\longrightarrow$ Non-English-speaking country of birth ----- English-speaking country of birth

Fig. 2. Age at arrival and English proficiency.

Notes: Figure plots the average ordinal measure of English proficiency, where 3, 2, 1, and 0 correspond to speaks "very well", "well", "not well", and "not at all", respectively. English proficiency is regression adjusted for age, sex and race. Two sets of outer lines correspond to $95 \%$ confident intervals. The sample corresponds to childhood immigrants aged 20 to 60 at the time of the 2011 Census.

Source: ONS Longitudinal Study.

early arrivers, the probabilities of having no qualifications and of teenage childbearing are similar across the two sets of immigrants. In contrast, among late arrivers, these probabilities tend to be higher for those from non-English-speaking countries, and to a greater extent in panel (a). Turning to panel (c), late arrivers from non-English-speaking countries appear to have more children, but the pattern is not very clear. Regarding adult health, panel (d) indicates that immigrants from non-English-speaking countries generally report worse health, and to a greater extent among late arrivers.

Fig. 2 shows the relation between English language proficiency and age at arrival of immigrants in England and Wales who arrived in the UK when they were young (aged 0 to 16). The dashed and solid lines correspond to immigrants from English- and non-Englishspeaking countries, respectively. Fig. 2 shows that immigrants born in English-speaking countries are generally proficient in English (i.e., scoring between 2.9 and 3 in the ordinal measure of English proficiency, where 3 corresponds to "speaks very well") irrespective of their age at arrival. This is not surprising because they were exposed to English prior to their arrival in the UK. In contrast, immigrants born in non-English-speaking countries who arrived in the UK after age eight report having a poorer command of English than those

arrival alone cannot be used as an instrument as it has direct effects on immigrant social outcomes. 
who arrived before age eight. The two series start diverging at around age nine. For those individuals born in non-English-speaking countries, the later they arrived, the poorer their English is, on average..$^{5}$ This observation is consistent with the critical period hypothesis. The pattern observed in Fig. 2 leads us to parameterise age at arrival of individual $i$ born in country $c$ who arrived in the UK at age $a, \phi_{i c a}$, in the following manner:

$$
\phi_{i c a}=\max \left(0, a_{i}-8\right) \times I(i \text { born in a non }- \text { English }- \text { speaking country })
$$

where $\max \left(0, \operatorname{arrival}_{i}-8\right)$ measures the additional years after age eight for those who arrived in the UK after age eight, and zero otherwise. $I(\cdot)$ is an indicator function that equals one if the individual was born in a non-English-speaking country, and zero otherwise. An assumption underlying equation (2) is that there is no difference in English language proficiency between immigrants from the two sets of countries for those who arrived at age eight or before, but language proficiency and age at arrival are linearly related after age eight for immigrants born in non-English-speaking countries. ${ }^{6}$

Moreover, it is plausible that within non-English-speaking countries, there is heterogeneity in terms of languages spoken in home countries. Precisely, a language (e.g., Dutch) may be more similar to English than another language (e.g., Vietnamese), making it easier to learn English for those coming from a country where a home-country language is more similar to English. To account for this heterogeneity in similarity of home-country languages to English, instead of using the indicator function in equation (2), we follow Clarke and Isphording (2017) and use linguistic distance between English and the home-country language, $l d i s t_{c}$, to construct our instrument, $\theta_{i c a}$ :

$$
\theta_{i c a}=\max \left(0, a_{i}-8\right) \times \text { ldist }_{c}
$$

Using equation (3), the relation between proficiency in English and age at arrival, which corresponds to our first-stage equation, can be specified as follows:

$$
\text { proficiency }_{i c a}=\alpha_{0}+\alpha_{1} \theta_{i c a}+X_{i c a}^{\prime} \zeta+\iota_{c}+\kappa_{a}+u_{i c a}
$$

where the individual characteristics, $X_{i c a}$, and the parameter $\zeta$ are $K \times 1$ vectors, where $K$ is the number of variables capturing individual characteristics. $l_{c}$ and $\kappa_{a}$ are country-of-birth

\footnotetext{
${ }^{5}$ Fig. 2 shows age-at-arrival effects for immigrants born in English-speaking countries: Namely, a negative trend for late arrivers, which makes our first-stage estimates smaller compared to the situation where this trend is absent.

${ }^{6}$ The age eight is chosen as the cut-off value because, for those who arrived in the UK at age eight or before, there is no significant difference in English skills as adults irrespective of whether they come from English- or non-English-speaking countries (cf. Fig. 2). As there appears to be a kink at age 11 for those born in non-English-speaking countries, we also tried using age 11 as a cut-off value. Our results are not sensitive to the change in the cut-off value.
} 
and age-at-arrival fixed effects, respectively, and $u_{i c a}$ is the disturbance term.

\section{Data and sample}

\subsection{Data}

We use data from the ONS England and Wales Longitudinal Study, an individual-level dataset comprising linked census and life event records for $1 \%$ of the population of England and Wales. We make use of two datasets that are part of the longitudinal study: The 2011 Census for England and Wales, and the Live Births to Sample Mothers (LBSM), which contains information of live births to women usually resident in England and Wales taken from the birth registration and birth certificate for the period 1971 to $2011 .{ }^{7}$ We create our fertility outcomes using data from the LBSM dataset, and they apply only to mothers in our longitudinal-study dataset that are also present in the LBSM dataset. Our measures of fertility are: Birthweight of child, age of woman when her first child was born, an indicator for a woman having first child in her teens, and number of children born to a woman. This latter variable is a better measure of the actual number of children born to a mother than the usual census variable of number of children living in same household used in most studies that analyse census data (e.g., Bleakley and Chin, 2010).

Our measures on education and health are also obtained from the 2011 Census. We construct a set of education indicator variables from one single variable in the 2011 Census, which collects self-reported information on the highest level of education achieved by the individual. The 2011 Census also collects information on self-reported health, which is an ordinal measure ranging from 1 (very bad health) to 5 (very good health); from this variable, we derive two additional indicator variables: "good or very good health" and "bad or very bad health". We use an additional measure of health that comes from another question in the 2011 Census: An indicator variable for self-reported long-term health problems.

The variables capturing language skills and individual characteristics come from the 2011 Census. Using information on self-reported language skills, we construct our measure of English language skills, where 3, 2, 1, and 0 correspond to speaks English "very well", "well", "not well", "not at all", respectively. For individual characteristics, we control for dummy variables for sex, race, age, age at arrival, country of origin, and the highest level of education attained by any of the two parents of the individuals in our sample. The dummy variable for parental education equals one if any of the two parents has college education or above, and zero otherwise. Note that, for fertility regressions, we cannot include parental education as a control since controlling for it reduces sample size due to missing values

\footnotetext{
${ }^{7}$ The dataset contains a variable that records the number of children previously born alive to sample mother. Prior to May 2012, this information was only collected for births within marriage. The registrar records the number of previous live-born children that a woman has had by her present husband and any former husband. Therefore some births may have not been recorded, or were only recorded if the mother gave the relevant information to the registrar.
} 
in the data on parental education, making it not possible to precisely estimate first-stage effects. Although this is a limitation of our dataset regarding fertility analysis, our data still allows us to control for parental education in the analyses of education and health, and we are not aware of any other studies that control for parental education, which is a possible important omitted variable in the causal analysis of the effect of English skills on education.

To create our instrument for language skills, we use information on the country of birth and age at arrival of immigrants from the 2011 Census, ${ }^{8}$ and a measure of linguistic distance between English and home-country language. As the measure of linguistic distance, we use a variation of the Levenshtein distance computed by Isphording and Otten (2014). Following a procedure to evaluate phonetic similarity between different languages developed by the German Max Planck Institute for Evolutionary Anthropology, they compute the extent of similarity between languages in percentage where a lower number indicates a greater similarity. This measure of linguistic distance is a standardised and continuous measure of linguistic distance between languages based on phonetic similarity, where a higher number indicates a greater linguistic distance. Despite its purely descriptive nature that does not require any prior knowledge on language relations, this measure of linguistic distance is highly correlated with other linguistic distance measures such as those developed by linguists based on language trees that categorise languages to different families. We assign linguistic distance based on the predominant language of immigrants' country of birth. In the case of immigrants born in a multilingual country, the predominant native language of the multilingual country (except for lingua francas, which are languages used for communication between people with different native languages for, for example, commercial reasons) is assigned. For immigrants born in a country where English is an official language and the predominant language spoken, we assign linguistic distance of zero.

The data on origin-country characteristics that we use in the section of robustness checks have been obtained from the following sources: The data on education are from Barro and Lee (2013), data on cultural distance are from Spolaore and Wacziarg (2016), and all other country characteristics are obtained from the World Development Indicators 2015. ${ }^{9}$

\subsection{Sample}

\section{Age restriction}

Our empirical analysis is based on the sample of individuals in the Longitudinal-Study dataset who (i) lived in England and Wales at the time of the 2011 Census, (ii) are child-

\footnotetext{
${ }^{8}$ Age at arrival in the UK is derived from the date that a person last arrived to live in the UK and their age. Short visits away from the UK are not counted in determining the date that a person last arrived. The age of arrival is only applicable to usual residents who were not born in the UK and does not include usual residents born in the UK who have emigrated and since returned.

${ }^{9}$ The variables in the World Development Indicators were downloaded from http://data. worldbank.org/data-catalog/world-development-indicators
} 
hood immigrants and (iii) are aged 20 or above at the time of the 2011 Census. Childhood immigrants are defined as individuals born outside of the UK who arrived in the UK for the first time at age 16 or before. At this age, we assume that immigrants did not make their own migration decisions but followed their parents or guardians who migrated to the UK. For the sample used for the analysis of educational outcomes, the minimum age restriction is raised to 25 in order to allow individuals enough time to complete their education. In our analysis of health outcomes, we also impose the maximum age restriction of age 60 to deal with a possible issue of selective mortality. For fertility outcomes, our sample is restricted to females who have at least one child registered with the LBSM dataset. ${ }^{10}$

\section{Country classification}

To implement our identification strategy, we create two groups of immigrants: (i) Individuals born in countries where English is not an official language, and (ii) individuals born in countries where English is an official language and the predominant language spoken. ${ }^{11}$ The first group is our "treatment group" and the second group is our "control group". Note that individuals born in countries where English is an official language but not the predominant language spoken are excluded from our sample because it is not clear to what extent they were exposed to English prior to their arrival in the UK. This restriction implies that we are excluding from our sample some groups of immigrants who account for a significant proportion of immigrants in the UK, such as those born in India and Pakistan.

Table 1 reports descriptive statistics separately for early and late arrivers in the UK. Panel A shows that English language skills are not very different between early arrivers in the two sets of countries, but late arrivers born in non-English-speaking countries present a lower level of language proficiency than late arrivers born in English-speaking countries. As expected, linguistic distances are larger for immigrants born in non-English-speaking countries and zero for those born in English-speaking countries. A list of the countries of birth of immigrants by age-at-arrival group is presented in Appendix A.

\section{Results}

We begin by estimating equation (1) using the OLS estimator. ${ }^{12}$ Column (1) of Table 2 reports the OLS estimates of the effect of English language proficiency on the social outcomes

\footnotetext{
${ }^{10}$ Although not having a child can also be considered an outcome, our sample is restricted to females who have at least one child registered with the LBSM dataset. This is because not every woman who has at least one child has her child registered with the LBSM dataset, implying that, among females who do not appear in the LBSM dataset, we cannot distinguish those with at least one child and those without a child.

${ }^{11}$ To categorise countries, we used the World Almanac and Book of Facts 2011.

${ }^{12}$ Our measure of English language skills is an ordinal variable as described in Section 4.1. To take into account possible non-linear effects of language proficiency on immigrant social outcomes, we consider using an indicator variable for speaking English "very well". The results using this alternative measure of language proficiency are similar to our main results (see Online Appendix A).
} 


\section{Table 1}

Immigrant characteristics.

\begin{tabular}{|c|c|c|c|c|}
\hline & \multicolumn{2}{|c|}{ Arrived aged $0-8$} & \multicolumn{2}{|c|}{ Arrived aged 9-16 } \\
\hline & $\begin{array}{c}\text { Born in } \\
\text { Anglophone } \\
\text { country }\end{array}$ & $\begin{array}{c}\text { Born in } \\
\text { non-Anglophone } \\
\text { country }\end{array}$ & $\begin{array}{c}\text { Born in } \\
\text { Anglophone } \\
\text { country }\end{array}$ & $\begin{array}{c}\text { Born in } \\
\text { non-Anglophone } \\
\text { country }\end{array}$ \\
\hline \multicolumn{5}{|c|}{ A. Individual characteristics (All, aged 20 to 60 ) } \\
\hline $\begin{array}{l}\text { English proficiency, } \\
\text { ordinal measure }\end{array}$ & $\begin{array}{c}2.994 \\
(0.103)\end{array}$ & $\begin{array}{c}2.978 \\
(0.180)\end{array}$ & $\begin{array}{c}2.959 \\
(0.213)\end{array}$ & $\begin{array}{c}2.751 \\
(0.552)\end{array}$ \\
\hline Linguistic distance & $\begin{array}{c}0.000 \\
(0.000)\end{array}$ & $\begin{array}{c}0.933 \\
(0.104)\end{array}$ & $\begin{array}{c}0.000 \\
(0.000)\end{array}$ & $\begin{array}{c}0.966 \\
(0.077)\end{array}$ \\
\hline Parental education & $\begin{array}{c}0.259 \\
(0.438)\end{array}$ & $\begin{array}{c}0.274 \\
(0.446)\end{array}$ & $\begin{array}{c}0.215 \\
(0.411)\end{array}$ & $\begin{array}{c}0.182 \\
(0.386)\end{array}$ \\
\hline Age & $\begin{array}{c}40.408 \\
(11.248)\end{array}$ & $\begin{array}{c}33.616 \\
(11.850)\end{array}$ & $\begin{array}{c}40.546 \\
(13.804)\end{array}$ & $\begin{array}{c}28.704 \\
(10.397)\end{array}$ \\
\hline Female & $\begin{array}{c}0.517 \\
(0.500)\end{array}$ & $\begin{array}{c}0.511 \\
(0.500)\end{array}$ & $\begin{array}{c}0.496 \\
(0.500)\end{array}$ & $\begin{array}{c}0.467 \\
(0.499)\end{array}$ \\
\hline White & $\begin{array}{c}0.674 \\
(0.469)\end{array}$ & $\begin{array}{c}0.575 \\
(0.495)\end{array}$ & $\begin{array}{c}0.265 \\
(0.442)\end{array}$ & $\begin{array}{c}0.362 \\
(0.481)\end{array}$ \\
\hline Black & $\begin{array}{c}0.130 \\
(0.336)\end{array}$ & $\begin{array}{c}0.106 \\
(0.308)\end{array}$ & $\begin{array}{c}0.354 \\
(0.478)\end{array}$ & $\begin{array}{c}0.235 \\
(0.424)\end{array}$ \\
\hline Asian & $\begin{array}{c}0.157 \\
(0.364)\end{array}$ & $\begin{array}{c}0.130 \\
(0.336)\end{array}$ & $\begin{array}{c}0.341 \\
(0.474)\end{array}$ & $\begin{array}{c}0.225 \\
(0.418)\end{array}$ \\
\hline Other single race & $\begin{array}{c}0.008 \\
(0.091)\end{array}$ & $\begin{array}{c}0.135 \\
(0.342)\end{array}$ & $\begin{array}{c}0.007 \\
(0.083)\end{array}$ & $\begin{array}{c}0.129 \\
(0.335)\end{array}$ \\
\hline Multiracial & $\begin{array}{c}0.029 \\
(0.169)\end{array}$ & $\begin{array}{c}0.051 \\
(0.219)\end{array}$ & $\begin{array}{c}0.033 \\
(0.179)\end{array}$ & $\begin{array}{c}0.038 \\
(0.192)\end{array}$ \\
\hline \multicolumn{5}{|c|}{ B. Education (All, aged 25 and over) } \\
\hline No qualifications & $\begin{array}{c}0.068 \\
(0.252)\end{array}$ & $\begin{array}{c}0.081 \\
(0.273)\end{array}$ & $\begin{array}{c}0.105 \\
(0.307)\end{array}$ & $\begin{array}{c}0.202 \\
(0.402)\end{array}$ \\
\hline Compulsory & $\begin{array}{c}0.373 \\
(0.484)\end{array}$ & $\begin{array}{c}0.358 \\
(0.480)\end{array}$ & $\begin{array}{c}0.427 \\
(0.495)\end{array}$ & $\begin{array}{c}0.446 \\
(0.497)\end{array}$ \\
\hline Post-compulsory & $\begin{array}{c}0.624 \\
(0.485)\end{array}$ & $\begin{array}{c}0.638 \\
(0.481)\end{array}$ & $\begin{array}{c}0.573 \\
(0.495)\end{array}$ & $\begin{array}{c}0.550 \\
(0.498)\end{array}$ \\
\hline Academic degree & $\begin{array}{c}0.460 \\
(0.499)\end{array}$ & $\begin{array}{c}0.475 \\
(0.500)\end{array}$ & $\begin{array}{c}0.392 \\
(0.488)\end{array}$ & $\begin{array}{c}0.387 \\
(0.488)\end{array}$ \\
\hline
\end{tabular}




\section{Table 1}

Immigrant characteristics - continued.

C. Health (All, aged 20 to 60 )

\begin{tabular}{|c|c|c|c|c|}
\hline $\begin{array}{l}\text { Self-reported health, } \\
\text { ordinal measure }\end{array}$ & $\begin{array}{c}4.346 \\
(0.794)\end{array}$ & $\begin{array}{c}4.415 \\
(0.789)\end{array}$ & $\begin{array}{c}4.314 \\
(0.778)\end{array}$ & $\begin{array}{c}4.371 \\
(0.838)\end{array}$ \\
\hline Good or very good health & $\begin{array}{c}0.882 \\
(0.323)\end{array}$ & $\begin{array}{c}0.893 \\
(0.310)\end{array}$ & $\begin{array}{c}0.867 \\
(0.340)\end{array}$ & $\begin{array}{c}0.885 \\
(0.320)\end{array}$ \\
\hline Bad or very bad health & $\begin{array}{c}0.029 \\
(0.169)\end{array}$ & $\begin{array}{c}0.029 \\
(0.167)\end{array}$ & $\begin{array}{c}0.024 \\
(0.153)\end{array}$ & $\begin{array}{c}0.039 \\
(0.194)\end{array}$ \\
\hline Long-term health problem & $\begin{array}{c}0.091 \\
(0.288)\end{array}$ & $\begin{array}{c}0.084 \\
(0.278)\end{array}$ & $\begin{array}{c}0.090 \\
(0.286)\end{array}$ & $\begin{array}{c}0.099 \\
(0.298)\end{array}$ \\
\hline \multicolumn{5}{|l|}{ D. Fertility (Females, aged 20 and over) } \\
\hline Age at having first child & $\begin{array}{l}27.695 \\
(5.469)\end{array}$ & $\begin{array}{l}26.708 \\
(5.163)\end{array}$ & $\begin{array}{l}26.525 \\
(5.418)\end{array}$ & $\begin{array}{l}24.771 \\
(5.588)\end{array}$ \\
\hline Teenage mother & $\begin{array}{c}0.093 \\
(0.291)\end{array}$ & $\begin{array}{c}0.105 \\
(0.307)\end{array}$ & $\begin{array}{c}0.136 \\
(0.342)\end{array}$ & $\begin{array}{c}0.213 \\
(0.410)\end{array}$ \\
\hline Number of children born to mother & $\begin{array}{c}2.880 \\
(1.078)\end{array}$ & $\begin{array}{c}2.823 \\
(1.208)\end{array}$ & $\begin{array}{c}3.071 \\
(1.395)\end{array}$ & $\begin{array}{c}3.247 \\
(1.648)\end{array}$ \\
\hline Birthweight of child (kilogrammes) & $\begin{array}{c}3.322 \\
(0.592)\end{array}$ & $\begin{array}{c}3.365 \\
(0.573)\end{array}$ & $\begin{array}{c}3.192 \\
(0.585)\end{array}$ & $\begin{array}{c}3.331 \\
(0.559)\end{array}$ \\
\hline
\end{tabular}

Notes: Standard deviations are shown in parenthesis. The sample consists of individuals who were present in the 2011 Census for England and Wales, are childhood immigrants, and were aged 20 to 60 (panels A and C), 25 and over (panel B), or 20 and over (panel D) at the time of the 2011 Census. The first and last two columns correspond to early and late arrivers, respectively. Sample size varies by panel and column. Panels A and C contain 2,$273 ; 1,461 ; 1,298$ and 1,309 observations in columns 1 to 4, respectively. Panel B contains 2,053; 1,$003 ; 1,091$ and 653 observations per column. Sample sizes in panel D vary by outcome: age at having first child $(597 ; 301 ; 383$ and 284 in columns 1 to 4 , respectively), indicator for having child in her teens (942; 475; $738 ; 521)$, number of children born to mother $(669 ; 345 ; 482 ; 352)$, and child birthweight $(2,327 ; 1,142 ; 1,722$; 1,466).

Source: Authors' calculations based on the ONS Longitudinal Study. 
Table 2

OLS, IV, reduced-form, and first-stage estimates.

\begin{tabular}{|c|c|c|c|c|}
\hline \multirow[t]{3}{*}{ Dependent variable: } & \multicolumn{3}{|c|}{ Education, health or fertility } & \multirow{2}{*}{$\begin{array}{c}\text { English skills } \\
\text { First-stage }\end{array}$} \\
\hline & OLS & IV & Reduced-form & \\
\hline & (1) & (2) & (3) & (4) \\
\hline \multicolumn{5}{|c|}{ A. Education (All, aged 25 and over) } \\
\hline No qualifications & $\begin{array}{c}-0.280 * * * \\
(0.023)\end{array}$ & $\begin{array}{c}-0.434 * * * \\
(0.075)\end{array}$ & $\begin{array}{c}0.021 * * * \\
(0.007)\end{array}$ & $\begin{array}{c}-0.048 * * * \\
(0.003)\end{array}$ \\
\hline Compulsory & $\begin{array}{c}-0.227 * * * \\
(0.029)\end{array}$ & $\begin{array}{c}-0.276^{* *} \\
(0.129)\end{array}$ & $\begin{array}{l}0.013^{*} \\
(0.007)\end{array}$ & $\begin{array}{c}-0.048 * * * \\
(0.003)\end{array}$ \\
\hline Post-compulsory & $\begin{array}{c}0.234 * * * \\
(0.029)\end{array}$ & $\begin{array}{c}0.295^{* *} \\
(0.134)\end{array}$ & $\begin{array}{c}-0.014 * * \\
(0.007)\end{array}$ & $\begin{array}{c}-0.048 * * * \\
(0.003)\end{array}$ \\
\hline Academic degree & $\begin{array}{c}0.210 * * * \\
(0.021)\end{array}$ & $\begin{array}{c}0.299 * * \\
(0.126)\end{array}$ & $\begin{array}{c}-0.014 * * \\
(0.007)\end{array}$ & $\begin{array}{c}-0.048 * * * \\
(0.003)\end{array}$ \\
\hline \multicolumn{5}{|l|}{ B. Health (All, aged 20 to 60 ) } \\
\hline $\begin{array}{l}\text { Self-reported health, } \\
\text { ordinal measure }\end{array}$ & $\begin{array}{c}0.467 * * * \\
(0.051)\end{array}$ & $\begin{array}{c}0.370 * * \\
(0.157)\end{array}$ & $\begin{array}{c}-0.018 * * \\
(0.008)\end{array}$ & $\begin{array}{c}-0.047 * * * \\
(0.003)\end{array}$ \\
\hline Good or very good health & $\begin{array}{c}0.137 * * * \\
(0.018)\end{array}$ & $\begin{array}{c}0.052 \\
(0.064)\end{array}$ & $\begin{array}{l}-0.002 \\
(0.003)\end{array}$ & $\begin{array}{c}-0.047 * * * \\
(0.003)\end{array}$ \\
\hline Bad or very bad health & $\begin{array}{c}-0.082 * * * \\
(0.016)\end{array}$ & $\begin{array}{c}-0.085 * * \\
(0.038)\end{array}$ & $\begin{array}{c}0.004 * * \\
(0.002)\end{array}$ & $\begin{array}{c}-0.047 * * * \\
(0.003)\end{array}$ \\
\hline Long-term health problem & $\begin{array}{c}-0.129 * * * \\
(0.024)\end{array}$ & $\begin{array}{l}-0.055 \\
(0.054)\end{array}$ & $\begin{array}{c}0.003 \\
(0.003)\end{array}$ & $\begin{array}{c}-0.047 * * * \\
(0.003)\end{array}$ \\
\hline \multicolumn{5}{|c|}{ C. Fertility (Females, aged 20 and over) } \\
\hline Age at having first child & $\begin{array}{c}2.235^{* * *} \\
(0.533)\end{array}$ & $\begin{array}{l}-0.585 \\
(2.387)\end{array}$ & $\begin{array}{c}0.027 \\
(0.111)\end{array}$ & $\begin{array}{c}-0.047 * * * \\
(0.007)\end{array}$ \\
\hline Teenage mother & $\begin{array}{c}-0.117 * * * \\
(0.031)\end{array}$ & $\begin{array}{c}-0.233 * * * \\
(0.087)\end{array}$ & $\begin{array}{c}0.016 * * * \\
(0.005)\end{array}$ & $\begin{array}{c}-0.069 * * * \\
(0.005)\end{array}$ \\
\hline Number of children & $\begin{array}{c}-0.428 * * * \\
(0.154)\end{array}$ & $\begin{array}{l}-0.607 \\
(0.437)\end{array}$ & $\begin{array}{c}0.035 \\
(0.025)\end{array}$ & $\begin{array}{c}-0.058 * * * \\
(0.006)\end{array}$ \\
\hline $\begin{array}{l}\text { Child birthweight } \\
\text { (kilogrammes) }\end{array}$ & $\begin{array}{l}-0.013 \\
(0.036)\end{array}$ & $\begin{array}{l}-0.012 \\
(0.152)\end{array}$ & $\begin{array}{c}0.001 \\
(0.011)\end{array}$ & $\begin{array}{c}-0.072 * * * \\
(0.003)\end{array}$ \\
\hline
\end{tabular}

Notes: $* * * p<.01, * * p<.05$, and $* p<.10$. Standard errors are clustered by country of birth. First-stage and reduced-form are the estimates of the coefficients on the interaction of age at arrival and linguistic distance from the origin country. IV and OLS are the estimates of $\beta_{1}$ in equation (1) using IV and OLS estimators, respectively. Rows in each panel correspond to regressions for different outcomes of education, health and fertility. Sample size varies by outcome: 4,800 for the education outcomes; 6,341 for the health outcomes; and 1,$565 ; 2,676 ; 1,848$; and 6,657 for each of the fertility outcomes, respectively. All regressions control for dummy variables for sex, race, age, age at arrival, country of origin, and parental education. The F-statistics on the excluded instrument in column 4 range from 50 to 475 .

Source: Authors' calculations based on the ONS Longitudinal Study. 
of childhood immigrants in England and Wales, after controlling for individual characteristics and country-of-birth and age-at-arrival fixed effects. Panels A to $\mathrm{C}$ present results for education, health and fertility outcomes, respectively. The sample in panel $\mathrm{C}$ is restricted to mothers.

Panel A shows that better language skills are positively correlated with the likelihood of obtaining a higher level of educational qualifications; in particular, better language skills are significantly associated with a lower probability of having no qualifications or having only compulsory-level qualifications (rows 1 and 2), and are significantly associated with higher probabilities of having a post-compulsory qualification and an academic degree (rows 3 and 4). Turning to health outcomes for adults, panel B indicates that better English proficiency is significantly correlated with better self-reported health (rows 1 and 2) and lower probabilities of reporting bad or very bad health and having long-term health problems (rows 3 and 4). Fertility outcomes reported in panel $\mathrm{C}$ indicate that better English proficiency is significantly associated with a delay in the age at which a woman has her first child, a lower likelihood of teenage childbearing, and having fewer children (rows 1 to 3). However, English skills appear to have no significant association with child health measured by birthweight (row 4).

The problem with the OLS estimator of $\beta_{1}$ in equation (1) is that it will be biased if English proficiency is endogenous. To address this potential endogeneity issue, we estimate equation (1) using the IV estimator, where we use, as an instrument for English skills, the interaction of the excess age at arrival from age eight and linguistic distance between English and home-country language (see equation (3)). Table 2 presents the first-stage and reduced-form estimates of the effects of the instrument on English skills and social outcomes, respectively, and the IV estimates of the effects of English skills on the social outcomes. The first-stage estimates presented in column (4) range from roughly -0.05 to -0.07 . The estimates imply that, for example, for those born in a country with linguistic distance $100 \%$ (e.g., Cambodia), each year past age eight at arrival significantly decreases their English language skill ordinal measure by approximately 0.05 to 0.07 on average. The magnitudes of the coefficients imply that a person's English ordinal measure would be approximately lower by half of a unit if the person arrived from a non-English-speaking country at age 16 instead of at age eight. It is important for the identification that our instrument is not weak, meaning that the instrument and English language skills are highly correlated. A weak instrument is known to bias the IV estimator towards the probability limit of the corresponding OLS estimator. Stock et al. (2002) compute the critical value for the weak instrument test based on the first-stage F-statistic, and suggest that an F-statistic above roughly 10 makes IV inferences reliable. Note that, according to their test for weak instruments, our instrument is not weak because the F-statistics on the excluded instrument in column (4) range from roughly 50 to 475 (the t-statistics range from 7.1 to 21.8).

Turning to educational outcomes reported in panel A, the reduced-form estimates in col- 
umn (3) show that, among immigrants from non-English-speaking countries, after age eight, each additional year that passes before they arrive in the UK decreases their likelihood of obtaining higher levels of education qualifications. In line with these reduced-form estimates, the causal effects of interest reported in column (2) indicate that better English language skills significantly lower the likelihood of having no qualifications and a compulsory qualification (rows 1 and 2), and raise that of obtaining a post-compulsory qualification and an academic degree (rows 3 and 4). The point estimate indicates, for example, that a standard-deviation increase in English language skills, among immigrants from nonEnglish-speaking countries, reduces the probability of having no qualifications by approximately 0.18 . As fluency in the language used at school is likely to be a key component in the production of academic success, it is not surprising that individuals with better English skills have a higher level of educational attainment.

Focusing on adult health outcomes reported in panel B, the reduced-form estimates show that arriving after age eight significantly aggravates self-reported health (row 1) and increases the chance of reporting bad or very bad health (row 3). Consistent with these reduced-form estimates, the IV estimates in column (2) indicate that better English skills significantly improve self-reported health and reduce the likelihood of reporting bad or very bad health. For example, a standard-deviation increase in English skills raises the self-reported ordinal health by roughly 0.16 , corresponding to an increase of approximately $4 \%$ relative to the mean value for childhood immigrants who arrived after age eight from non-English-speaking countries.

Regarding fertility outcomes in panel C, column (3) indicates that, for each year at arrival past age eight, the probability of teenage childbearing significantly increases (row 2). The size of the coefficient indicates that the probability that an immigrant woman gives birth in her teens increases by approximately 0.13 if she arrived at age 16 instead of age eight. The causal effects of interest in column (2) show that better English skills significantly reduce the likelihood of becoming a teenage mother (row 2). However, English skills seem to have no significant impact on other fertility outcomes (rows 1, 3 and 4).

\section{Comparison with previous evidence}

Having found the impact of English skills on immigrant social outcomes, it would be informative to compare our IV estimates with existing evidence from other countries. We restrict our attention to causal studies that use comparable ordinal measures of English skills and outcome variables to our studies.

Among US immigrants, the IV effects of English skills on the likelihood of having a high school diploma range between 0.306 and 0.400, and the effects on the likelihood of having a Bachelor's degree or more range between 0.092 and 0.313 (Akbulut-Yuksel et al., 2011), ${ }^{13}$ implying that the marginal effects of English skills on education outcomes broadly

\footnotetext{
${ }^{13}$ Akbulut-Yuksel et al. (2011) study the effects of English skills for Hispanic and non-Hispanic immigrants,
} 
lie within the similar ranges for UK and US immigrants. Turning to fertility analysis, among US immigrants, the IV effects on the number of children living in same household varies from -0.351 to -0.765 (Akbulut-Yuksel et al., 2011) and from -0.190 to -0.591 (Bleakley and Chin, 2010). ${ }^{14}$ Our IV estimate for the number of biological children, -0.607, lies within the same range as those obtained using the US data. However, our point estimate is insignificant, unlike the US studies which generally find significant effects on the number of children. This could be because of a smaller sample size in our study relative to the US studies. We are not aware of any causal study that analyses the effect of language on teenage childbearing that we can compare our findings to.

Among immigrants in Australia, the IV effects on self-reported health (ordinal measure ranging between 1 and 5 , where 5 is the best health) is -0.282 for males and 1.544 for females (Guven and Islam, 2015). Although it is counter-intuitive that they find the negative effect of English skills for males, when the full sample is used, the estimate is 0.835. The marginal effect of English skills on health in the Australian study is slightly less than double the size of our estimate, 0.467 , which could be due to, among others, a bias caused by not controlling for parental characteristics in their estimation equation.

\section{Comparison of OLS and IV estimates}

When comparing OLS and IV estimates, our general findings are that OLS estimates tend to be greater in absolute terms for health outcomes. The health outcomes are only outcomes that are self-reported unlike education and fertility outcomes for which we use more objective measures. If a person is lenient in self-assessment, it is possible that the person reports to have a better health and a better English language proficiency compared to a person who is stricter in self-assessment. If this is the case, the leniency contained in the error term of equation (1) can cause upward bias in the OLS estimator of the effects of English skills, possibly leading to greater OLS estimates relative to IV estimates in absolute terms.

In the case of education and some fertility outcomes, IV estimates are greater in absolute terms. For example, the IV estimate is roughly one and a half times larger than the OLS estimate for the probability of having no qualifications (cf. columns (1) and (2) of Table 2). It is possible that unobserved individual characteristics, such as ability, biases the OLS estimator upward, but at the same time measurement error possibly correlated with our measure of language proficiency biases the OLS estimator downward. It could be the case, for example, that immigrants surrounded by native English speakers tend to report their proficiency being poor, while those surrounded by other non-English-speaking immigrants may report their proficiency being fluent irrespective of their true English proficiency. In fact, self-reported categorical language measures are found to contain substantial measurement

and obtain different estimates for the two groups of immigrants.

${ }^{14}$ Bleakley and Chin (2010) study the differential effects by sex, and obtain different estimates for males and females. 
error (Dustmann and van Soest, 2001). If the downward bias caused by measurement error, known as attenuation bias, outweighs the upward bias caused by unobserved heterogeneity, IV estimates will be greater than OLS estimates.

It is also plausible that there is non-classical measurement error (i.e., measurement error that is correlated with the unobserved true English proficiency) in our self-reported measure of English proficiency. For example, it is likely that there is measurement error that tends to be negative for those who are proficient because there is no room to over-report their proficiency at the top end of the categorical measure of English proficiency, and vice versa for those who are not proficient. As a result, if there are many observations at the bounds of our categorical English proficiency measure, the unobserved true English proficiency and measurement error will be negatively correlated. This is an important concern because, in our sample, a significant proportion of individuals report to speak English "very well", which is the top category in our measure of proficiency. Under the presence of non-classical measurement error, the OLS estimator is negatively biased and the IV estimator can be positively biased (Kane et al., 1999) ${ }^{15}$ which can help explain why IV estimates are greater than the OLS estimates for education and some fertility outcomes. ${ }^{16}$ Previous studies using US census self-reported measures of English proficiency to analyse the effects of English proficiency on education and fertility outcomes also find that IV estimates tend to be greater than OLS estimates in absolute terms (Bleakley and Chin, 2004, 2010).

\section{The role of parental characteristics}

This section addresses the concern that our main results are driven by differences in parental characteristics of immigrants born in English- and non-English-speaking countries. It could be the case that parental characteristics that affect the social outcomes of immigrants are different between the immigrants from the two sets of countries, and parents with different characteristics may make different decisions about the timing of immigration. For example, highly educated parents of immigrants from non-English-speaking countries may decide to migrate to the UK when their children are relatively young to make it easier for them to

\footnotetext{
${ }^{15}$ When there is non-classical measurement error in a non-binary categorical variable, the direction of the bias in the IV estimator is ambiguous as it depends on the nature of measurement error in the region of language proficiency affected by the instrument (Kane et al., 1999). In case the IV estimator is positively biased, the true effects will lie between OLS and IV estimates. In case the IV estimator is also negatively biased, the findings that both OLS and IV estimates are significant imply that the true effects on educational attainment and fertility are possibly greater than those reported in Table 2 . It is not possible to further investigate to which direction the IV estimator is biased, because we are not aware of any objective measure of English proficiency that is linked to the ONS Longitudinal Study. However, it is worth noting that the possible presence of non-classical measurement error will not invalidate our findings that language skills significantly affect some immigrant social outcomes, although it will affect the interpretations of the sizes of the effects.

${ }^{16}$ When English proficiency is measured by a binary indicator, OLS and IV estimates will bound the true effect of English proficiency: Namely, the OLS and IV estimates provide the lower and upper bounds of the true effect, respectively (e.g., Brachet, 2008; Kane et al., 1999). In this regard, our OLS and IV estimates in Online Appendix A, based on the model where English proficiency is measured by a dummy variable (that equals one if a person speaks English "very well", and zero otherwise), provide the lower and upper bounds of the true effect of English proficiency, respectively.
} 


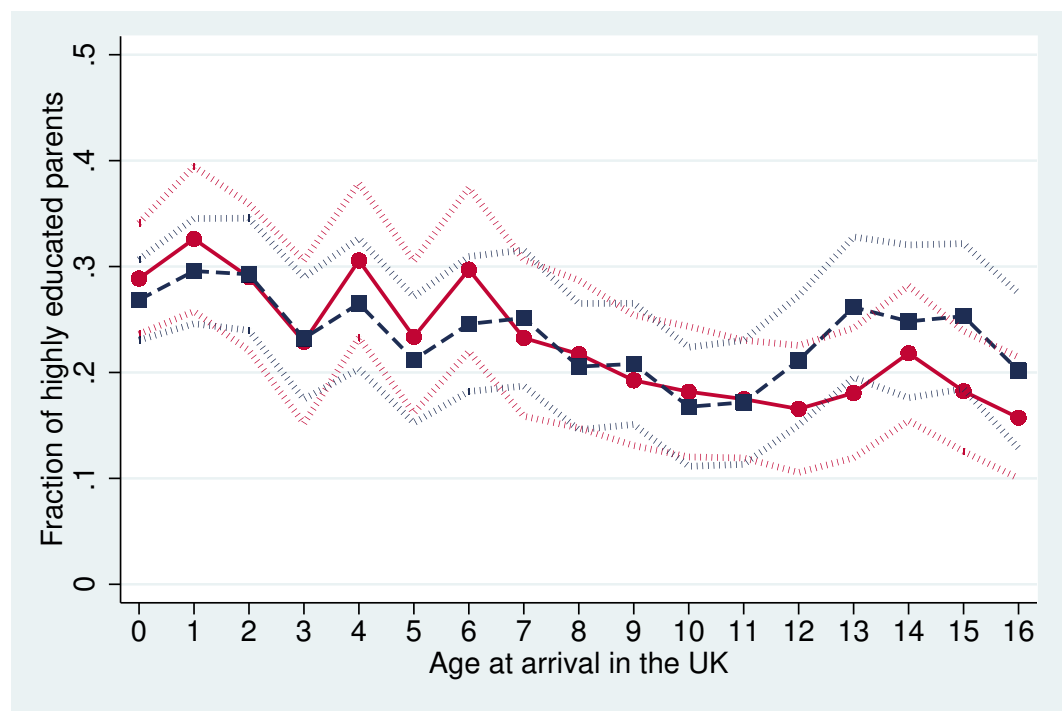

$\longrightarrow$ Non-English-speaking country of birth ----- English-speaking country of birth

Fig. 3. Fraction of parents with college education or above.

Notes: The dashed and solid lines correspond to immigrants born in English- and non-English-speaking countries, respectively. Two sets of outer lines correspond to $95 \%$ confident intervals. The sample corresponds to childhood immigrants aged 20 to 60 at the time of the 2011 Census.

Source: ONS Longitudinal Study.

adapt to the new environment. If this was the case, the distributions of parental characteristics across age at arrival could be different between the two sets of immigrants, and our IV estimates may be capturing the effects of not only English skills but also differences in parental characteristics.

As we have been controlling for parental education in every regression, any difference in observable parental education across the two sets of immigrants has already been accounted for. Nevertheless, one might still be concerned that there is a difference in the distributions of unobserved parental characteristics across age at arrival between the two sets of immigrants. In an attempt to investigate this possibility, first, we plot parental education measured by the fraction of parents with college education or above in Figure 3. The solid and dashed lines correspond to immigrants born in non-English- and English-speaking countries, respectively. Figure 3 indicates that, for early arrivers (i.e., those who arrived at age eight or earlier), the two series follow similar patterns. For late arrivers, the two series slightly diverge and the parents from non-English-speaking countries appear to be less educated, indicating the possibility that differences in unobserved parental characteristics could exist, although the difference in Figure 3 is insignificant.

Second, we regress parental education on age-at-arrival dummy variables, linguistic distance, and the interaction of the excess age at arrival from age eight and linguistic distance 
Table 3

Balancing test on parental education.

\begin{tabular}{lcc}
\hline \hline \multirow{2}{*}{ Dependent variable: } & \multicolumn{2}{c}{ Parental education } \\
\cline { 2 - 3 } & \multicolumn{1}{c}{$(1)$} \\
\hline \multirow{2}{*}{ Linguistic distance } & 0.008 & \\
Linguistic distance $\times \max \left(0, a_{i}-8\right)$ & $(0.057)$ & \\
Treatment & -0.013 & \\
& $(0.009)$ & 0.021 \\
Treatment $\times \max \left(0, a_{i}-8\right)$ & & $(0.053)$ \\
& & -0.014 \\
& & $(0.009)$ \\
\hline \hline
\end{tabular}

Notes: Standard errors are clustered by country of birth. Column (1) estimates the model, edupa $a_{i c a}=\alpha_{0}+\alpha_{1}$ ldist $_{c}+\alpha_{2}$ ldist $_{c} \times \max \left(0, a_{i}-8\right)+X^{\prime} \gamma+u_{\text {ica }}$, where edupa is a dummy variable for parental education that equals one if any of the two parents has college education or above, ldist is linguistic distance, $\max \left(0, a_{i}-8\right)$ equals additional years after age eight for those who arrived after age eight and zero otherwise, and $X$ is a vector of age-at-arrival dummy variables. Column (2) estimates the model, edupa $_{\text {ica }}=\beta_{0}+\beta_{1}$ treat $_{c}+\beta_{2}$ treat $_{c} \times \max \left(0, a_{i}-8\right)+X^{\prime} \gamma+\varepsilon_{\text {ica }}$, where treat is an indicator for being born in a non-English-speaking country. The sample corresponds to childhood immigrants aged 20 to 60 at the time of the 2011 Census.

Source: Authors' calculations based on the ONS Longitudinal Study.

(i.e., our instrument for English skills, see equation (3)). The results are presented in column (1) of Table 3. In column (2), we regress parental education on age-at-arrival dummy variables, an indicator for being born in a non-English-speaking country, and the interaction of this indicator and the excess age at arrival from age eight (see equation (2)). Table 3 indicates that the coefficient estimates on the interaction terms in both columns are insignificant, providing some evidence in support of the possibility that unobserved parental characteristics are not differently related to age-at-arrival groups across the two sets of immigrants.

Finally, we run regressions with and without parental characteristics as a control to see whether our IV estimates of the effect of English proficiency are sensitive to the omission of parental characteristics. If it is the case that our instrument is systematically related to parental characteristics, omitting parental characteristics from our model would affect the IV estimates of the effect of English proficiency. Appendix B reports our IV results for education and health outcomes with and without parental education as a control. ${ }^{17}$ The results indicate that parental education has a strong impact on all of the education and health

\footnotetext{
${ }^{17}$ For fertility regressions, as mentioned in Section 4.1, we cannot include parental education as a control since controlling for it reduces sample size due to missing values in the data on parental education, making it not possible to precisely estimate first-stage effects.
} 
outcomes. However, after omitting parental education, the IV estimates of the effects of English proficiency largely remain similar. Turning to the first-stage effect of the instrument on English skills, in the education regressions, the estimates are -0.048 (15.31) and -0.048 (15.33) in the models with and without parental education, respectively, where t-statistics are reported in parentheses. For the health regressions, the first-stage estimates are -0.047 (15.39) and -0.047 (15.44) in the models with and without parental education, respectively. The two sets of estimates are very similar to each other, providing some evidence in favour of the possibility that the instrument is not systematically related to unobserved parental characteristics.

\subsection{Mechanisms at work}

We have found that better English skills significantly affect immigrant social outcomes. This subsection explores whether the effects of language on health and fertility are operating through education. It may be the case that better English skills improve the educational attainment of immigrants, which in turn affects health through, among others, income, occupational choice, and health behaviour such as drinking (e.g., see Cutler and Lleras-Muney, 2008). Education can also affect fertility: It may be the case that better English skills improve the educational attainment and career opportunities of women, which could in turn reduce the incidence of teenage childbearing or the number of children they have because, for example, their opportunity cost of having children increases (e.g., Cygan-Rehm and Maeder, 2013; Monstad et al., 2008).

To explore the possible role of education, we control for measures of education, in addition to English proficiency, in our regressions for health and fertility outcomes. As measures of education, we include a set of dummy variables that equal one if the person has no qualifications, a post-compulsory qualification and an academic degree, respectively, and zero otherwise. Our reference group is those with compulsory education. A caveat is that estimates of the effects of English proficiency will no longer have causal interpretations because education is likely endogenous. Despite this limitation, we present these results as suggestive evidence of a possible role that education plays in determining immigrant health and fertility outcomes. Even-numbered columns in Table 4 present IV estimates of the effects of English proficiency after controlling for education. For comparison, we present the base results without controlling for education in adjacent columns.

Panel A reports health outcomes. After controlling for education, the IV estimates of the effects of language have been diminished, and the effects on self-reported health and the likelihood of reporting bad or very bad health have become insignificant (columns (2) and (6)). In contrast, education appears to have strong effects on health as is found by many previous studies (e.g., Cutler and Lleras-Muney, 2008). These results provide evidence in favour of the possibility that education could be a key mediator for the health outcomes of immigrants. 


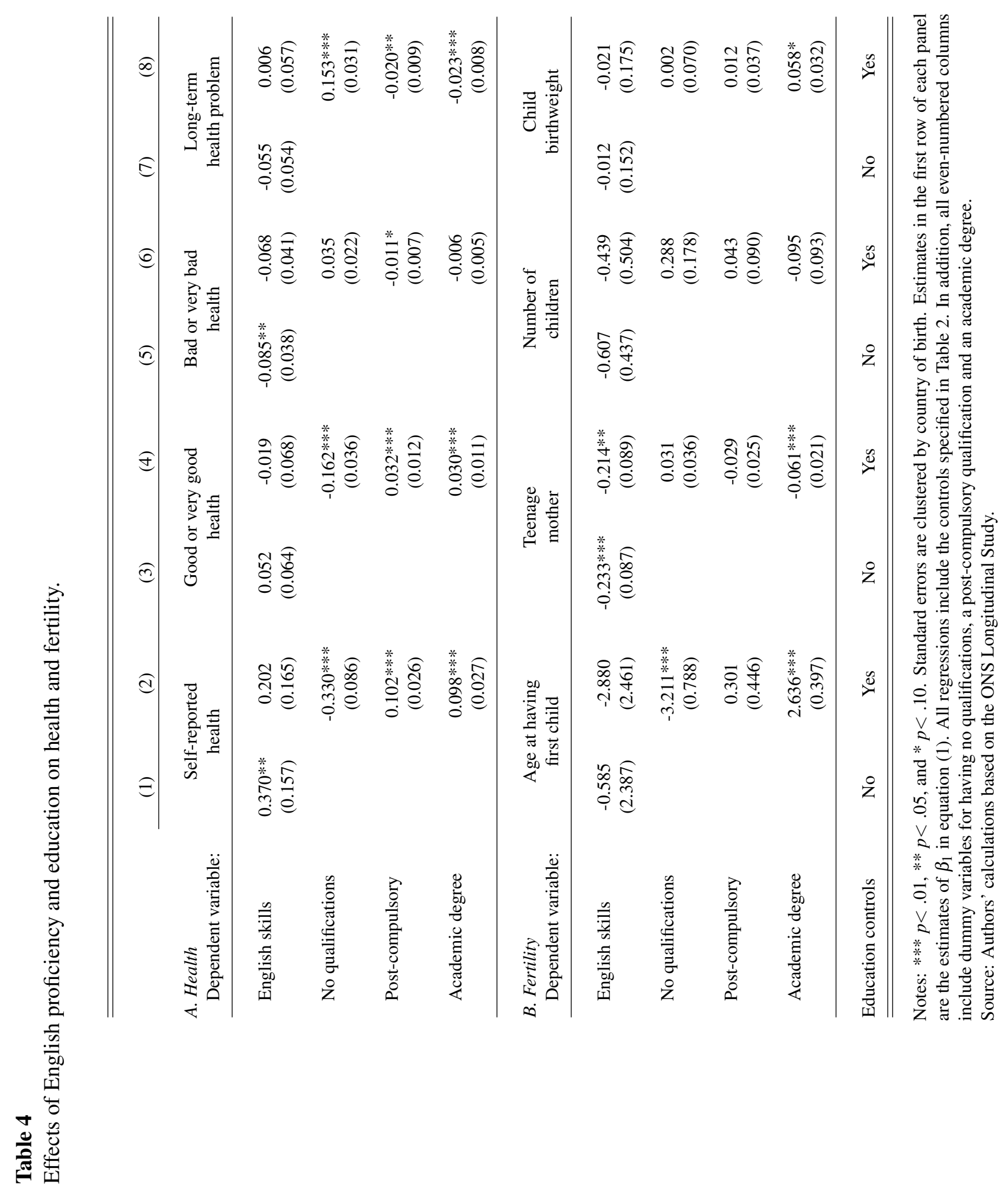


Fertility outcomes reported in panel B provide a different picture: Education appears to affect the timing of having a child, likelihood of teenage childbearing, and child health. However, even after the inclusion of education controls in column (4), the effect of language on the likelihood of teenage childbearing remains unchanged. The analysis based on US data also finds that the effects of English proficiency on fertility remain significant after controlling for measures of education (Bleakley and Chin, 2010), suggesting that there is likely to be other important channels than education through which language affects fertility choices of immigrant women. For example, better English skills may promote immigrant women to discover British social norms and adopt them by, for example, promoting communication with natives or facilitating the processing of information on media. Many immigrant women from non-English-speaking countries come from countries with higher adolescent fertility rates than the UK, and for women from countries with higher adolescent fertility rates, adapting to British norms means a reduction in teenage childbearing.

\section{Robustness checks}

We now turn to address the concern that immigrants born in English- and non-Englishspeaking countries could be different in other aspects, aside from language, that could also affect their social outcomes. To address this concern, two different strategies will be employed: We (i) consider different sample specifications in which samples are restricted to immigrants born in countries that are likely to be less heterogeneous, and (ii) control for interactions of age at arrival with different origin-country characteristics.

A key assumption for our IV strategy to identify the causal effects of language skills is that those born in English- and non-English-speaking countries are exposed to the same ageat-arrival effects, except for the language effect. Under this assumption, immigrants born in English-speaking countries can be used to partial out age-at-arrival effects that immigrants from non-English-speaking countries are exposed to. However, it could be reasonable to doubt the validity of this assumption; for example, it could be that English-speaking countries are economically, culturally, and institutionally more similar to the UK, making this age-at-arrival effects differ between immigrants from the two groups of countries. This type of concerns might be less severe in the UK context than in the US context as the average characteristics of immigrants from the two groups of countries might be more similar in the case of UK immigrants: $47 \%$ of UK immigrants are highly educated, compared to $34 \%$ in the US, and $34 \%$ of UK immigrants come from OECD high-income countries, compared to only $14 \%$ for US immigrants (OECD, 2012). In addition, we have been controlling for country-of-origin fixed effects in every regression, which absorb any background characteristics affecting the immigrant social outcomes specific to a country of origin that do not vary across age at arrival.

However, one might still be concerned that the age-at-arrival effects across the two sets 
of immigrants are very different. To address this concern, we further restrict our sample and retain only immigrants from countries that may be less heterogeneous from each other. Unavoidably we must pay the cost of losing more observations, although the more we restrict our sample, the less heterogeneous the sample becomes. For fertility outcomes, first-stage estimates are not strong enough to compute the IV estimates when we further divide samples because of the relatively small original sample sizes. Thus, we report results only for education and health in Table 5.

Panel A summarises the results for educational outcomes using different sample specifications. Row 1 presents our base results for comparison, whereas rows 2 and 3 exclude from the base sample immigrants from Europe and Commonwealth countries, respectively. The European countries have close economic and political ties and cultural similarities with the UK due to, for example, the existence of the European Union and a long history of interactions between countries, possibly making the age-at-arrival effects different for European immigrants. Likewise, Commonwealth countries also share some commonalities with the UK regarding, for example, culture and legal systems. Omitting immigrants from these countries that have special ties with the UK may make the two groups of countries less heterogeneous. The results reported in rows 2 and 3 are qualitatively similar to our main findings.

In a similar vein, to make our sample more homogeneous in terms of income level, we divide the sample into immigrants from countries with below- and above-median gross domestic product (GDP) per capita. Origin-country GDP per capita could reflect numerous aspects of origin countries that potentially affect the immigrant social outcomes. For example, high GDP countries may, on average, have better educational and healthcare systems and a higher life expectancy, and all of these characteristics may affect the immigrant social outcomes. The results reported in rows 4 and 5 are qualitatively similar to our base results. A point to note is that point estimates are greater for low-income countries, implying that the impact of fluency in English is greater for low-income countries. It could be the case that the education systems in low-income countries are less similar to the British system, making it harder for immigrants from these countries to adapt to the British system if they have poor English skills.

Panel B of Table 5 reports the results for health outcomes. We found in the previous section that better English skills significantly improve self-reported health and reduce the chance of reporting bad or very bad health (row 1). These results are generally not sensitive to the omissions of European and Commonwealth countries (rows 2 and 3) and appear to be driven by immigrants born in low-GDP countries (row 4), although some of these effects are now imprecisely estimated. A possible interpretation is that immigrants from high-income countries might find it easy to adapt to the British system irrespective of their proficiency in English because their healthcare systems and/or medical culture are more similar to that of the UK, implying that they have less to adapt to, and vice versa for those from low-income 


\section{Table 5}

IV estimates using alternative samples.

\begin{tabular}{|c|c|c|c|c|}
\hline \multirow{2}{*}{$\begin{array}{l}\text { A. Education } \\
\text { Dependent variable: }\end{array}$} & $(1)$ & $(2)$ & (3) & (4) \\
\hline & No qualifications & Compulsory & Post-compulsory & Academic degree \\
\hline 1. All & $\begin{array}{c}-0.434 * * * \\
(0.075)\end{array}$ & $\begin{array}{c}-0.276 * * \\
(0.129)\end{array}$ & $\begin{array}{c}0.295 * * \\
(0.134)\end{array}$ & $\begin{array}{c}0.299 * * \\
(0.126)\end{array}$ \\
\hline 2. No Europe & $\begin{array}{c}-0.402 * * * \\
(0.094)\end{array}$ & $\begin{array}{l}-0.293 * \\
(0.159)\end{array}$ & $\begin{array}{l}0.318^{*} \\
(0.164)\end{array}$ & $\begin{array}{c}0.291 * * \\
(0.143)\end{array}$ \\
\hline 3. No Commonwealth & $\begin{array}{c}-0.448 * * * \\
(0.106)\end{array}$ & $\begin{array}{c}-0.352 * * \\
(0.175)\end{array}$ & $\begin{array}{c}0.374 * * \\
(0.176)\end{array}$ & $\begin{array}{c}0.460 * * \\
(0.188)\end{array}$ \\
\hline 4. Low GDP & $\begin{array}{c}-0.441 * * * \\
(0.092)\end{array}$ & $\begin{array}{c}-0.572 * * \\
(0.227)\end{array}$ & $\begin{array}{c}0.626^{* * * *} \\
(0.204)\end{array}$ & $\begin{array}{c}0.512 * * \\
(0.230)\end{array}$ \\
\hline 5. High GDP & $\begin{array}{c}-0.438 * * * \\
(0.115)\end{array}$ & $\begin{array}{c}-0.290 * \\
(0.162)\end{array}$ & $\begin{array}{l}0.307 * \\
(0.157)\end{array}$ & $\begin{array}{l}0.283^{*} \\
(0.163)\end{array}$ \\
\hline $\begin{array}{l}\text { B. Health } \\
\text { Dependent variable: }\end{array}$ & $\begin{array}{l}\text { Self-reported } \\
\text { health }\end{array}$ & $\begin{array}{l}\text { Good or very good } \\
\text { health }\end{array}$ & $\begin{array}{l}\text { Bad or very bad } \\
\text { health }\end{array}$ & $\begin{array}{c}\text { Long-term } \\
\text { health problems }\end{array}$ \\
\hline 1. All & $\begin{array}{c}0.370 * * \\
(0.157)\end{array}$ & $\begin{array}{c}0.052 \\
(0.064)\end{array}$ & $\begin{array}{c}-0.085^{* *} \\
(0.038)\end{array}$ & $\begin{array}{l}-0.055 \\
(0.054)\end{array}$ \\
\hline 2. No Europe & $\begin{array}{c}0.406 * * * \\
(0.150)\end{array}$ & $\begin{array}{c}0.048 \\
(0.057)\end{array}$ & $\begin{array}{c}-0.090 * * \\
(0.040)\end{array}$ & $\begin{array}{l}-0.064 \\
(0.046)\end{array}$ \\
\hline 3. No Commonwealth & $\begin{array}{c}0.379 \\
(0.242)\end{array}$ & $\begin{array}{c}0.138 \\
(0.084)\end{array}$ & $\begin{array}{l}-0.074 \\
(0.050)\end{array}$ & $\begin{array}{l}-0.116 \\
(0.085)\end{array}$ \\
\hline 4. Low GDP & $\begin{array}{c}0.451 * * \\
(0.174)\end{array}$ & $\begin{array}{c}0.081 \\
(0.066)\end{array}$ & $\begin{array}{l}-0.071 \\
(0.050)\end{array}$ & $\begin{array}{c}-0.097 * * \\
(0.046)\end{array}$ \\
\hline 5. High GDP & $\begin{array}{c}0.270 \\
(0.275)\end{array}$ & $\begin{array}{c}0.057 \\
(0.096)\end{array}$ & $\begin{array}{l}-0.057 \\
(0.062)\end{array}$ & $\begin{array}{l}-0.043 \\
(0.111)\end{array}$ \\
\hline
\end{tabular}

Notes: $* * * p<.01, * * p<.05$, and $* p<.10$. Standard errors are clustered by country of birth. The estimates shown are the IV estimates of $\beta_{1}$ in equation (1), using the controls specified in Table 2. Each row corresponds to a different sample specification: Full sample (row 1), sample excluding Europe (row 2), sample excluding Commonwealth (row 3); and immigrants born in countries with below- and above-median GDP (rows 4 and 5) .

Source: Authors' calculations based on the ONS Longitudinal Study. 
countries.

We now restrict our sample in a different manner in an attempt to make immigrants from the two sets of countries less heterogeneous from each other. Precisely, we compute propensity score for being born in a non-English-speaking country, and use it as a tool to systematically select a sample before running regressions. The propensity score is defined as follows:

$$
p\left(D_{i}=1 \mid X_{i}\right)=F\left(X_{i}\right)=\frac{1}{1+e^{-\left(\mu_{0}+X_{i}^{\prime} v\right)}}
$$

where $p(\cdot)$ is the probability, $D_{i}$ is an indicator function for being born in a non-Englishspeaking country, $F(\cdot)$ is the logistic function, and $X_{i}$ is a vector of individual characteristics, which are dummy variables for age, sex and race. Following Crump et al. (2009), we estimate equation (5) using a pooled treatment and observational-control sample, and retain in our sample only the observations with $0.1<p\left(X_{i}\right)<0.9-$ i.e., the observations with the estimated probability of being treated is more than 0.1 but less than 0.9. ${ }^{18}$ Screening the sample in this way ensures that the screened sample contains only the observations that belong to the common support of covariate distributions for the treatment and control groups. ${ }^{19}$ Results using the samples screened on propensity score, reported in Table 6, are broadly qualitatively similar to the base results.

We now take a different approach to address the concern that immigrants from Englishand non-English-speaking countries are exposed to different non-language age-at-arrival effects, by controlling for interactions of age at arrival with various origin-country characteristics. Unless otherwise stated, we use origin-country characteristics in 1980. Results are summarised in Table 7, where base results are presented in column (1) for comparison. Panel A reports results for educational outcomes, where column (2) controls for an interaction of age at arrival with country-of-origin per student public education expenditure in secondary education. If non-English-speaking countries have, on average, a higher (or lower) education expenditure than English-speaking countries and the effects of origincountry education expenditure vary by age at arrival, our instrument for English skills captures the compound effects of language proficiency and differential per student education expenditure in the origin country. In a similar spirit, column (3) controls for an interaction with origin-country average years of schooling. Results are not sensitive to the inclusion of

\footnotetext{
${ }^{18}$ The idea of using propensity score as a tool to systematically select a sample before running regressions is suggested by Crump et al. (2009), which is different from using propensity score as a basis for an estimator. An example of another application of this method is Angrist and Pischke (2009) who evaluate a programme to provide work experience, based on the original studies by LaLonde (1986) and Dehejia and Wahba (1999). Comparing the results based on experimental sample, unscreened observational sample, and propensity-score screened sample using the restriction of $0.1<p\left(X_{i}\right)<0.9$, Angrist and Pishke illustrate that the propensityscore screened results come very close to the experimental results.

${ }^{19}$ In fact, the restriction, $0.1<p\left(X_{i}\right)<0.9$, is stronger than common support restriction. In other words, imposing this restriction more narrowly selects sample than retaining only the observations that belong to the common support of covariate distributions for the treatment and control groups.
} 
Table 6

IV estimates using propensity-score screened sample.

\begin{tabular}{|c|c|c|c|c|}
\hline & \multicolumn{2}{|c|}{ Base results } & \multicolumn{2}{|c|}{$\begin{array}{c}\text { Sample screened on } \\
\text { dummies for age, sex and race }\end{array}$} \\
\hline & IV & First-stage & IV & First-stage \\
\hline & (1) & (2) & (3) & (4) \\
\hline \multicolumn{5}{|l|}{ A. Education (All, aged 25 and over) } \\
\hline No qualifications & $\begin{array}{c}-0.434 * * * \\
(0.075)\end{array}$ & $\begin{array}{c}-0.048 * * * \\
(0.003)\end{array}$ & $\begin{array}{c}-0.440 * * * \\
(0.074)\end{array}$ & $\begin{array}{c}-0.047 * * * \\
(0.003)\end{array}$ \\
\hline Compulsory & $\begin{array}{c}-0.276^{* *} \\
(0.129)\end{array}$ & $\begin{array}{c}-0.048 * * * \\
(0.003)\end{array}$ & $\begin{array}{c}-0.310 * * \\
(0.133)\end{array}$ & $\begin{array}{c}-0.047 * * * \\
(0.003)\end{array}$ \\
\hline Post-compulsory & $\begin{array}{c}0.295^{* *} \\
(0.134)\end{array}$ & $\begin{array}{l}-0.048 * * * \\
(0.003)\end{array}$ & $\begin{array}{c}0.335^{* *} \\
(0.134)\end{array}$ & $\begin{array}{c}-0.047 * * * \\
(0.003)\end{array}$ \\
\hline Academic degree & $\begin{array}{c}0.299 * * \\
(0.126)\end{array}$ & $\begin{array}{l}-0.048 * * * \\
(0.003)\end{array}$ & $\begin{array}{c}0.229 \\
(0.154)\end{array}$ & $\begin{array}{c}-0.047 * * * \\
(0.003)\end{array}$ \\
\hline \multicolumn{5}{|l|}{ B. Health (All, aged 20 to 60 ) } \\
\hline $\begin{array}{l}\text { Self-reported health, } \\
\text { ordinal measure }\end{array}$ & $\begin{array}{c}0.370 * * \\
(0.157)\end{array}$ & $\begin{array}{c}-0.047 * * * \\
(0.003)\end{array}$ & $\begin{array}{c}0.385^{* *} \\
(0.175)\end{array}$ & $\begin{array}{c}-0.047 * * * \\
(0.003)\end{array}$ \\
\hline Good or very good health & $\begin{array}{c}0.052 \\
(0.064)\end{array}$ & $\begin{array}{l}-0.047 * * * \\
(0.003)\end{array}$ & $\begin{array}{c}0.060 \\
(0.068)\end{array}$ & $\begin{array}{c}-0.047 * * * \\
(0.003)\end{array}$ \\
\hline Bad or very bad health & $\begin{array}{c}-0.085 * * \\
(0.038)\end{array}$ & $\begin{array}{l}-0.047 * * * \\
(0.003)\end{array}$ & $\begin{array}{l}-0.069 \\
(0.043)\end{array}$ & $\begin{array}{c}-0.047 * * * \\
(0.003)\end{array}$ \\
\hline Long-term health problem & $\begin{array}{l}-0.055 \\
(0.054)\end{array}$ & $\begin{array}{l}-0.047 * * * \\
(0.003)\end{array}$ & $\begin{array}{l}-0.061 \\
(0.061)\end{array}$ & $\begin{array}{c}-0.047 * * * \\
(0.003)\end{array}$ \\
\hline \multicolumn{5}{|c|}{ C. Fertility (Females, aged 20 and over) } \\
\hline Age at having first child & $\begin{array}{l}-0.585 \\
(2.387)\end{array}$ & $\begin{array}{c}-0.047 * * * \\
(0.007)\end{array}$ & $\begin{array}{l}-0.703 \\
(2.955)\end{array}$ & $\begin{array}{c}-0.039 * * \\
(0.007)\end{array}$ \\
\hline Teenage mother & $\begin{array}{c}-0.233 * * * \\
(0.087)\end{array}$ & $\begin{array}{c}-0.069 * * * \\
(0.005)\end{array}$ & $\begin{array}{c}-0.228 * * \\
(0.093)\end{array}$ & $\begin{array}{c}-0.066^{* * *} \\
(0.005)\end{array}$ \\
\hline Number of children & $\begin{array}{l}-0.607 \\
(0.437)\end{array}$ & $\begin{array}{c}-0.058 * * * \\
(0.006)\end{array}$ & $\begin{array}{l}-0.618 \\
(0.523)\end{array}$ & $\begin{array}{c}-0.053 * * * \\
(0.006)\end{array}$ \\
\hline Child birthweight (kilogrammes) & $\begin{array}{l}-0.012 \\
(0.152)\end{array}$ & $\begin{array}{c}-0.072 * * * \\
(0.003)\end{array}$ & $\begin{array}{l}-0.120 \\
(0.167)\end{array}$ & $\begin{array}{c}-0.068 * * * \\
(0.003)\end{array}$ \\
\hline
\end{tabular}

Notes: *** $p<.01, * * p<.05$, and $* p<.10$. Standard errors are clustered by country of birth. IV is the estimates of $\beta_{1}$ in equation (1), and first-stage is the estimates of $\alpha_{1}$ in equation (4). Columns 1 and 2 use the base sample (refer to Table 2 for sample sizes and the F-statistics on the excluded instrument). Columns 3 and 4 use samples screened on the propensity score calculated using equaiton (5) where dummy variables for age, sex and race are used as individual characteristics, $X_{i}$. Sample sizes in the last columns vary by panel: 4,609 and 5,963 observations in panels A and B, respectively. Sample sizes in panel C vary by outcome: age at having first child, 1,484; indicator for having child in her teens, 2,475; number of children born to mother, 1,753; and child birthweight, 6,161. The F-statistics in column 4 range from 35 to 398.

Source: Authors' calculations based on the ONS Longitudinal Study. 
Table 7

IV estimates with additional controls for origin-country characteristics.

\begin{tabular}{|c|c|c|c|c|}
\hline & \multirow{2}{*}{$\begin{array}{c}\text { Base results } \\
\text { (1) }\end{array}$} & \multicolumn{3}{|c|}{$\begin{array}{l}\text { Control for country of origin characteristics } \\
\qquad(\mathrm{x} \text { age at arrival) }\end{array}$} \\
\hline & & (2) & (3) & (4) \\
\hline \multicolumn{2}{|c|}{ A. Education (All, aged 25 and over) } & Education expenditure & Years of schooling & Cultural distance \\
\hline No qualifications & $\begin{array}{l}-0.434 * * * \\
(0.075)\end{array}$ & $\begin{array}{l}-0.472 * * * \\
(0.073)\end{array}$ & $\begin{array}{l}-0.395^{* * * *} \\
(0.106)\end{array}$ & $\begin{array}{l}-0.355^{* * *} \\
(0.090)\end{array}$ \\
\hline Compulsory & $\begin{array}{c}-0.276^{* *} \\
(0.129)\end{array}$ & $\begin{array}{l}-0.277^{*} \\
(0.159)\end{array}$ & $\begin{array}{l}-0.219 \\
(0.147)\end{array}$ & $\begin{array}{l}-0.424 * * * \\
(0.143)\end{array}$ \\
\hline Post-compulsory & $\begin{array}{c}0.295 * * \\
(0.134)\end{array}$ & $\begin{array}{l}0.302 * \\
(0.166)\end{array}$ & $\begin{array}{c}0.253 \\
(0.156)\end{array}$ & $\begin{array}{c}0.447 * * * \\
(0.142)\end{array}$ \\
\hline Academic degree & $\begin{array}{c}0.299 * * \\
(0.126)\end{array}$ & $\begin{array}{c}0.329 * * \\
(0.158)\end{array}$ & $\begin{array}{l}0.235^{*} \\
(0.134)\end{array}$ & $\begin{array}{c}0.370^{* *} \\
(0.156)\end{array}$ \\
\hline \multicolumn{2}{|l|}{ B. Health (All, aged 20 to 60 ) } & Health expenditure & Child mortality rate & Cultural distance \\
\hline $\begin{array}{l}\text { Self-reported health, } \\
\text { ordinal measure }\end{array}$ & $\begin{array}{r}0.370^{* *} \\
(0.157)\end{array}$ & $\begin{array}{c}0.372 * * \\
(0.155)\end{array}$ & $\begin{array}{l}0.289^{*} \\
(0.158)\end{array}$ & $\begin{array}{l}0.377 * \\
(0.195)\end{array}$ \\
\hline Good or very good health & $\begin{array}{c}0.052 \\
(0.064)\end{array}$ & $\begin{array}{l}(0.050) \\
(0.065)\end{array}$ & $\begin{array}{c}0.017 \\
(0.066)\end{array}$ & $\begin{array}{c}0.041 \\
(0.075)\end{array}$ \\
\hline Bad or very bad health & $\begin{array}{c}-0.085 * * \\
(0.038)\end{array}$ & $\begin{array}{l}-0.071 * \\
(0.037)\end{array}$ & $\begin{array}{l}-0.058 \\
(0.037)\end{array}$ & $\begin{array}{l}-0.061 \\
(0.050)\end{array}$ \\
\hline Long-term health problem & $\begin{array}{l}-0.055 \\
(0.054)\end{array}$ & $\begin{array}{l}-0.017 \\
(0.063)\end{array}$ & $\begin{array}{l}-0.028 \\
(0.057)\end{array}$ & $\begin{array}{l}-0.045 \\
(0.068)\end{array}$ \\
\hline \multicolumn{2}{|c|}{ C. Fertility (Females, aged 20 and over) } & $\begin{array}{l}\text { Adolescent } \\
\text { fertility rate }\end{array}$ & Fertility rate & Cultural distance \\
\hline Age at having first child & $\begin{array}{l}-0.585 \\
(2.387)\end{array}$ & $\begin{array}{l}-0.308 \\
(1.931)\end{array}$ & $\begin{array}{l}-0.406 \\
(2.021)\end{array}$ & $\begin{array}{l}-0.150 \\
(2.392)\end{array}$ \\
\hline Teenage mother & $\begin{array}{c}-0.233^{* * * *} \\
(0.087)\end{array}$ & $\begin{array}{c}-0.228 * * * \\
(0.084)\end{array}$ & $\begin{array}{c}-0.221^{* * *} \\
(0.083)\end{array}$ & $\begin{array}{c}-0.219 * * \\
(0.088)\end{array}$ \\
\hline Number of children & $\begin{array}{l}-0.607 \\
(0.437)\end{array}$ & $\begin{array}{l}-0.607 \\
(0.390)\end{array}$ & $\begin{array}{l}-0.595 \\
(0.391)\end{array}$ & $\begin{array}{l}-0.601 \\
(0.442)\end{array}$ \\
\hline $\begin{array}{l}\text { Child birthweight } \\
\text { (kilogrammes) }\end{array}$ & $\begin{array}{l}-0.012 \\
(0.152)\end{array}$ & $\begin{array}{l}-0.086 \\
(0.120)\end{array}$ & $\begin{array}{l}-0.049 \\
(0.132)\end{array}$ & $\begin{array}{l}-0.091 \\
(0.134)\end{array}$ \\
\hline
\end{tabular}

Notes: $* * * p<.01, * * p<.05$, and $* p<.10$. Standard errors are clustered by country of birth. The estimates shown are the IV estimates of $\beta_{1}$ in equation (1) for the outcomes indicated in each row, using the controls specified in Table 2 (column 1) in addition to interactions of age at arrival with origin-country characteristics (columns 2 to 4). In panel A, these origin-country characteristics are: per student public education expenditure, average years of schooling, and cultural distance; in panel B, per capita health expenditure, child mortality rate, and cultural distance; and in panel $\mathrm{C}$, adolescent fertility rate, total fertility rate, and cultural distance. Sample size varies by specification.

Source: Authors' calculations based on the ONS Longitudinal Study. 
these additional controls.

Finally, in column (4), we control for an interaction of age at arrival with cultural distance between the UK and origin country. If English-speaking countries are culturally closer to the UK and the effects of cultural distance on social outcomes vary by age at arrival, our instrument may capture the compound effects of English skills and (non-language) cultural differences. Although this is highly plausible, a challenge to implement this idea is to quantify cultural distance as the concept of culture is not quantitative in nature. We address this challenge by using cultural distance measured by genetic distance, obtained from Spolaore and Wacziarg (2016). They argue that the genetic distance, measuring the closeness of populations in terms of genes, reflects time since the populations shared the same ancestors. Over time, the ancestors transmit to their descendants not only their biological traits (i.e., genes) but also their cultural traits, such as habits and values, and this transmission occurs with variation. Populations that are genetically far from each other had more time to diverge in terms of cultural traits, and this divergence can in turn create barriers to human interactions. Spolaore and Wacziarg (2016) document that genetic distance of populations is significantly positively correlated with a wide array of measures of cultural differences. Based on their idea, we use the genetic distance as a summary measure of cultural distance. The results that control for its interaction with age at arrival, reported in column (4), are broadly similar to the base results.

Health outcomes are reported in panel B. Columns (2) to (4) control for interactions with origin-country per capita health expenditure, origin-country child mortality rate, and cultural distance to the UK, respectively. Note that the data used for per capita health expenditure is in 1995, the earliest year for which data is available. Turning to fertility outcomes reported in panel C, columns (2) to (4) control for an interaction with adolescent fertility rates, defined as the number of births per 1,000 women aged between 15 to 19 , an interaction with total fertility rates, and an interaction with cultural distance, respectively. Results are generally robust to the inclusion of these additional variables.

\section{Conclusion}

Policy at present stresses that English proficiency is a key to the integration of immigrants in the UK, but there is little research evidence on how English skills affect social outcomes of the immigrant population in the UK. From an international perspective, the UK is a particularly interesting country for studying the phenomenon of assimilation because the composition of immigrants in the UK is very different from that of the US, the country that has been most extensively studied: $47 \%$ of the immigrants in the UK come from a country with English as an official language, compared to $20 \%$ in the US; $47 \%$ of UK immigrants are highly educated, compared to $34 \%$ in the US; and $34 \%$ of UK immigrants come from high-income countries, compared to only $14 \%$ of US immigrants (OECD, 2012). 
In this paper, we study how English language skills affect education, health and fertility outcomes of childhood immigrants in England and Wales, using a unique dataset that links individual-level data from the 2011 Census for England and Wales and the LBSM. We study the causal effect of language skills using an IV estimation strategy where an interaction of age at arrival in the UK with linguistic distance between the origin-country language and English is used as an instrument for English language proficiency. The idea of using age at arrival to construct the instrument is based on the critical period of language acquisition hypothesis, stating that a person exposed to a language within the critical period of language acquisition (i.e., childhood) learns the language more easily. The hypothesis implies that immigrants born in linguistically distant countries who arrived in the UK at a young age would on average have better English skills than those who arrived at an older age.

Our IV estimates suggest that the educational achievement, self-reported health, and fertility behaviour of immigrants are influenced by their ability to speak English. We find that better English language skills significantly raise the likelihood of having an academic degree and a post-compulsory qualification, and reduce that of having no qualifications and a compulsory qualification as the highest level of education qualification obtained. We also find that being proficient in English significantly improves self-reported adult health and decreases the likelihood of teenage childbearing, but has no effect on child health. Regarding mechanisms, supplementary analysis suggests that higher educational attainment as a result of better English language skills is a possible channel though which English proficiency improves self-reported health. In contrast, in the case of fertility analysis, the effect of English skills remains significant even after controlling for education, implying that, for fertility behaviour, there are other mediators apart from education.

Our results have important policy implications. First, giving support to immigrants to learn and improve their English language skills may allow them to make the best of their education in school and further studies. This in turn may improve their educational attainment and affect their self-reported health. Second, specific English-learning programs at school for young immigrants who arrived in the UK at age eight or later would be particularly beneficial for them, since having arrived in the UK after the critical period of language acquisition makes it more difficult to learn the language. Specific language support classes could have an important impact in their capability to obtain qualifications or pursue higher academic degree studies. In addition, our results contribute to the public debate on the integration of immigrants, providing some evidence against the idea that claims that the lack of integration of immigrants into the UK society is merely due to their social or cultural preferences. We have found that there is a constraint that immigrants face to integrate aside from possible cultural preferences: proficiency in English, and that alleviating this constraint (e.g., supporting immigrants to learn English) could be a successful way to help immigrants better integrate into the UK society. 


\section{Appendix A}

Immigrants by country of birth.

\begin{tabular}{|c|c|c|c|c|c|}
\hline \multicolumn{3}{|l|}{ A. English-speaking countries } & \multicolumn{3}{|c|}{ B. Non-English-speaking countries } \\
\hline A-1. Arrived aged $0-8$ & $N$ & $\%$ & $B$-1. Arrived aged $0-8$ & $N$ & $\%$ \\
\hline Ireland & 297 & 13.1 & Cyprus & 161 & 11.0 \\
\hline Kenya & 285 & 12.5 & Somalia & 101 & 6.9 \\
\hline South Africa & 193 & 8.5 & Italy & 86 & 5.9 \\
\hline United States & 177 & 7.8 & Turkey & 80 & 5.5 \\
\hline Australia & 171 & 7.5 & France & 58 & 4.0 \\
\hline Canada & 165 & 7.3 & Malaysia & 54 & 3.7 \\
\hline Singapore & 155 & 6.8 & Iraq & 43 & 2.9 \\
\hline Uganda & 124 & 5.5 & Netherlands & 42 & 2.9 \\
\hline Malta & 105 & 4.6 & Vietnam & 41 & 2.8 \\
\hline Jamaica & 98 & 4.3 & Iran & 40 & 2.7 \\
\hline Nigeria & 85 & 3.7 & Germany & 39 & 2.7 \\
\hline Zambia & 66 & 2.9 & Saudi Arabia & 37 & 2.5 \\
\hline Zimbabwe & 56 & 2.5 & Spain & 37 & 2.5 \\
\hline New Zealand & 43 & 1.9 & Portugal & 33 & 2.3 \\
\hline Gibraltar & 41 & 1.8 & Yemen & 31 & 2.1 \\
\hline Ghana & 29 & 1.3 & Egypt & 29 & 2.0 \\
\hline Guyana & 24 & 1.1 & Afghanistan & 29 & 2.0 \\
\hline Trinidad and Tobago & 16 & 0.7 & Malawi & 29 & 2.0 \\
\hline Sierra Leone & 15 & 0.7 & Belgium & 22 & 1.5 \\
\hline Isle of Man & 15 & 0.7 & Libya & 22 & 1.5 \\
\hline Total top 20 & 2,160 & 95.0 & Total top 20 & 1,014 & 69.4 \\
\hline A-2. Arrived aged $9-16$ & $N$ & $\%$ & $B$-2. Arrived aged $9-16$ & $N$ & $\%$ \\
\hline Kenya & 323 & 24.9 & Somalia & 246 & 18.8 \\
\hline Uganda & 148 & 11.4 & Turkey & 116 & 8.9 \\
\hline Jamaica & 142 & 10.9 & Afghanistan & 75 & 5.7 \\
\hline Nigeria & 94 & 7.2 & Cyprus & 59 & 4.5 \\
\hline South Africa & 93 & 7.2 & Iraq & 46 & 3.5 \\
\hline Zimbabwe & 79 & 6.1 & Vietnam & 43 & 3.3 \\
\hline Ireland & 69 & 5.3 & Poland & 41 & 3.1 \\
\hline Ghana & 48 & 3.7 & Yemen & 37 & 2.8 \\
\hline United States & 36 & 2.8 & Kosovo & 37 & 2.8 \\
\hline Singapore & 25 & 1.9 & Portugal & 35 & 2.7 \\
\hline Zambia & 23 & 1.8 & Germany & 30 & 2.3 \\
\hline Guyana & 23 & 1.8 & Iran & 29 & 2.2 \\
\hline Canada & 23 & 1.8 & Malawi & 28 & 2.1 \\
\hline Australia & 21 & 1.6 & France & 27 & 2.1 \\
\hline Sierra Leone & 15 & 1.2 & China & 25 & 1.9 \\
\hline Trinidad and Tobago & 14 & 1.1 & Italy & 21 & 1.6 \\
\hline New Zealand & 13 & 1.0 & Sudan & 21 & 1.6 \\
\hline St Vincent and the Grenadines & 11 & 0.8 & Saudi Arabia & 19 & 1.5 \\
\hline Rwanda & 10 & 0.8 & Nepal & 19 & 1.5 \\
\hline St Lucia & 10 & 0.8 & Malaysia & 17 & 1.3 \\
\hline Total top 20 & 1,220 & 94.0 & Total top 20 & 971 & 74.2 \\
\hline
\end{tabular}

Notes: Panels A and B present English- and non-English-speaking countries, respectively. N refers to the number of individuals by country of birth for the top 20 countries present in our sample for those who arrived in the UK between age 0 and 8 (upper panels) and between 9 and 16 (lower panels).

Source: Authors' calculations based on the ONS Longitudinal Study. 


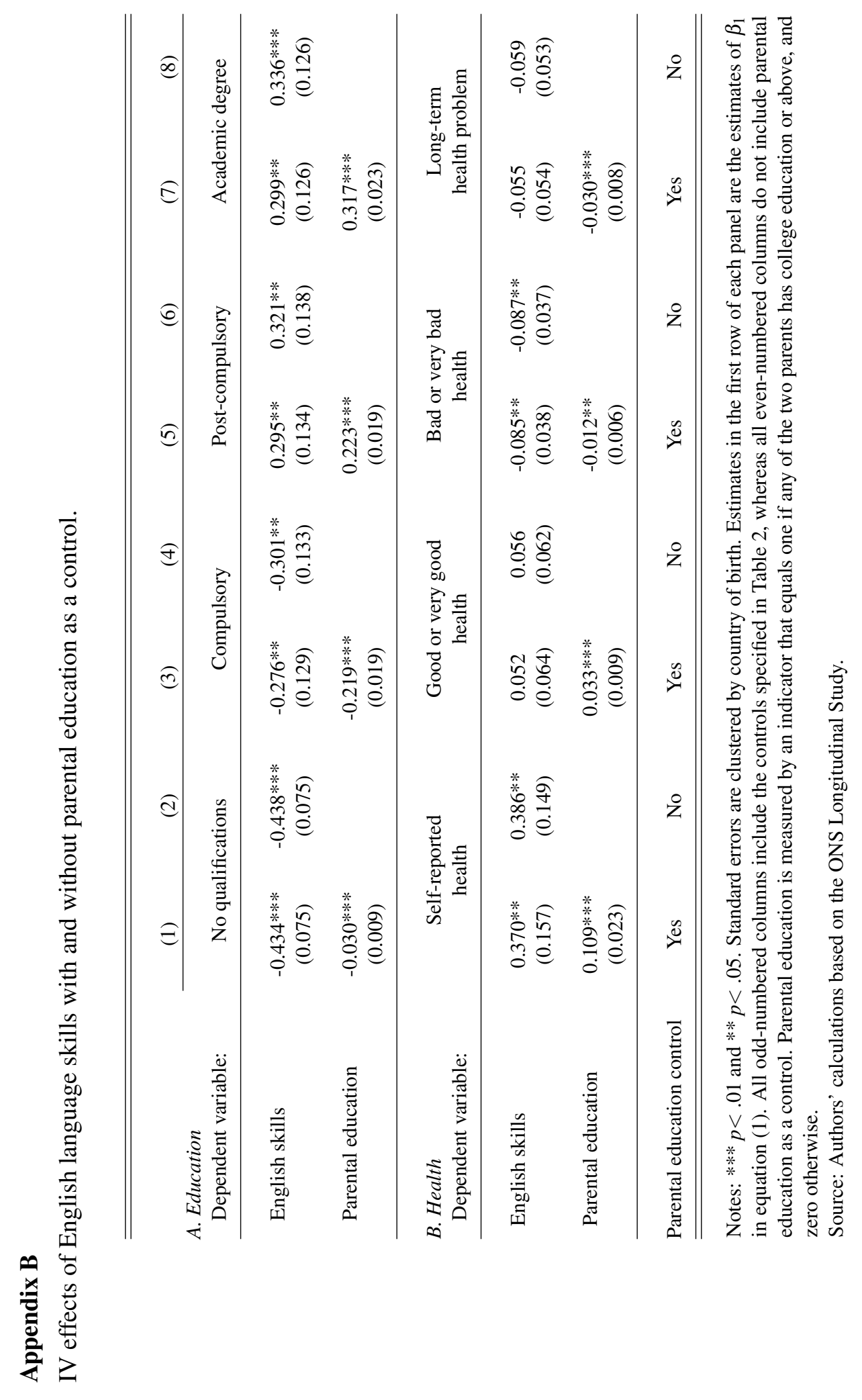




\section{References}

Adsera, A., Ferrer, A., 2014. Factors influencing the fertility choices of child immigrants in Canada. Population Studies 68, 65-79.

Akbulut-Yuksel, M., Bleakley, H., Chin, A., 2011. The effects of English proficiency among childhood immigrants: Are Hispanics different?, in: Leal, D.L., Trejo, S.J. (Eds.), Latinos and the Economy. Springer New York. Immigrants and Minorities, Politics and Policy, pp. 255-283.

Angrist, J.D., Pischke, J.S., 2009. Mostly harmless econometrics: An empiricist's companion. Princeton University Press, Princeton.

Barro, R., Lee, J.W., 2013. A new data set of educational attainment in the world 19502010. Journal of Development Economics 104, 184-198.

Bauer, A.M., Chen, C.N., Alegria, M., 2012. Prevalence of physical symptoms and their association with race, ethnicity and acculturation in the United States. General Hospital Psychiatry 34, $323-331$.

Bleakley, H., Chin, A., 2004. Language skills and earnings: Evidence from childhood immigrants. The Review of Economics and Statistics 86, 481-496.

Bleakley, H., Chin, A., 2010. Age at arrival, English proficiency, and social assimilation among US immigrants. American Economic Journal: Applied Economics 2, 165-92.

Böhlmark, A., 2008. Age at immigration and school performance: A siblings analysis using Swedish register data. Labour Economics 15, 1366 - 1387.

Brachet, T., 2008. Maternal Smoking, Misclassification, and Infant Health. MPRA Paper 21466. University Library of Munich, Germany.

Chiswick, B.R., Miller, P.W., 2014. International migration and the economics of language, in: Chiswick, B.R., Miller, P.W. (Eds.), Handbook on the Economics of International Migration. 1 ed.. Elsevier. volume 1A. chapter 5.

Clarke, A., Isphording, I.E., 2017. Language barriers and immigrant health. Health Economics $26,765-778$.

Cohen Goldner, S., Epstein, G.S., 2014. Age at immigration and high school dropouts. IZA Journal of Migration 3, 19.

Corak, M., 2011. Age at immigration and the education outcomes of children. IZA Discussion Papers 6072. Institute for the Study of Labor (IZA). 
Cortes, K.E., 2006. The effects of age at arrival and enclave schools on the academic performance of immigrant children. Economics of Education Review 25, 121-132.

Crump, R.K., Hotz, V.J., Imbens, G.W., Mitnik, O.A., 2009. Dealing with limited overlap in estimation of average treatment effects. Biometrika 96, 187-199.

Cutler, D., Lleras-Muney, A., 2008. Education and health: Evaluating theories and evidence. Russell Sage Foundation, New York.

Cygan-Rehm, K., Maeder, M., 2013. The effect of education on fertility: Evidence from a compulsory schooling reform. Labour Economics 25, 35 - 48.

Dehejia, R.H., Wahba, S., 1999. Causal effects in nonexperimental studies: Re-evaluating the evaluation of training programs. Journal of the American Statistical Association 94, $1053-1062$.

Dustmann, C., van Soest, A., 2001. Language fluency and earnings: Estimation with misclassified language indicators. The Review of Economics and Statistics 83, 663-674.

Glick, J., White, M., 2003. Academic trajectories of immigrant youths: Analysis within and across cohorts. Demography 40, 759-783.

Guven, C., Islam, A., 2015. Age at migration, language proficiency, and socioeconomic outcomes: Evidence from Australia. Demography 52, 513-542.

Isphording, I.E., Otten, S., 2014. Linguistic barriers in the destination language acquisition of immigrants. Journal of Economic Behavior \& Organization 105, 30 - 50.

Janssen, S., 2010. The world almanac and book of facts 2011. Infobase Learning, New York.

Jayaweera, H., 2014. Health of migrants in the UK: What do we know? The Migration Observatory. University of Oxford. URL: http://migrationobservatory • ox . ac.uk/briefings/health-migrants-uk-what-do-we-know. Accessed on 11 December 2014.

Kane, T.J., Rouse, C.E., Staiger, D., 1999. Estimating returns to schooling when schooling is misreported. Working Paper 7235. National Bureau of Economic Research.

Kimbro, R.T., Gorman, B.K., Schachter, A., 2012. Acculturation and self-rated health among Latino and Asian immigrants to the United States. Social Problems 59, pp. 341363.

LaLonde, R.J., 1986. Evaluating the econometric evaluations of training programs with experimental data. The American Economic Review 76, 604-620. 
Lee, S., ONeill, A., Ihara, E., Chae, D., 2013. Change in self-reported health status among immigrants in the United States: Associations with measures of acculturation. PLOS ONE 8, 76494.

Lenneberg, E.H., 1967. Biological foundations of language. Wiley, New York.

Lichter, D.T., Johnson, K.M., Turner, R.N., Churilla, A., 2012. Hispanic assimilation and fertility in new U.S. destinations. International Migration Review 46, 767-791.

Miranda, P.Y., Gonzalez, H.M., Tarraf, W., 2011. Pathways between acculturation and health: Does the measure matter? Hispanic Journal of Behavioral Sciences 33, 524-539.

Monstad, K., Propper, C., Salvanes, K.G., 2008. Education and fertility: Evidence from a natural experiment. Scandinavian Journal of Economics 110, 827-852.

OECD, 2012. Settling in: OECD indicators of immigrant integration 2012 Accessed on 11 December 2014.

Spolaore, E., Wacziarg, R., 2016. Ancestry and development: New evidence. Discussion Papers Series, Department of Economics, Tufts University 0820. Department of Economics, Tufts University.

Stock, J.H., Wright, J.H., Yogo, M., 2002. A survey of weak instruments and weak identification in generalized method of moments. Journal of Business \& Economic Statistics 20, 518-29. 


\section{Online Appendix A}

Alternative measure of English language skills.

\begin{tabular}{|c|c|c|c|c|}
\hline \multirow[t]{3}{*}{ Dependent variable: } & \multicolumn{3}{|c|}{ Education, health or fertility } & $\begin{array}{l}\text { Dummy for } \\
\text { English ability }\end{array}$ \\
\hline & OLS & IV & Reduced-form & First-stage \\
\hline & (1) & (2) & (3) & (4) \\
\hline
\end{tabular}

A. Education (All, aged 25 and over)

\begin{tabular}{|c|c|c|c|c|}
\hline No qualifications & $\begin{array}{c}-0.328 * * * \\
(0.029)\end{array}$ & $\begin{array}{c}-0.569 * * * \\
(0.100)\end{array}$ & $\begin{array}{c}0.021 * * * \\
(0.007)\end{array}$ & $\begin{array}{c}-0.037 * * * \\
(0.002)\end{array}$ \\
\hline Compulsory & $\begin{array}{c}-0.280 * * * \\
(0.039)\end{array}$ & $\begin{array}{c}-0.362 * * \\
(0.167)\end{array}$ & $\begin{array}{l}0.013^{*} \\
(0.007)\end{array}$ & $\begin{array}{c}-0.037 * * * \\
(0.002)\end{array}$ \\
\hline Post-compulsory & $\begin{array}{l}0.294 * * * \\
(0.039)\end{array}$ & $\begin{array}{c}0.387 * * \\
(0.172)\end{array}$ & $\begin{array}{c}-0.014 * * \\
(0.007)\end{array}$ & $\begin{array}{c}-0.037 * * * \\
(0.002)\end{array}$ \\
\hline Academic degree & $\begin{array}{c}0.284 * * * \\
(0.029)\end{array}$ & $\begin{array}{c}0.393 * * \\
(0.166)\end{array}$ & $\begin{array}{c}-0.014 * * \\
(0.007)\end{array}$ & $\begin{array}{c}-0.037 * * * \\
(0.002)\end{array}$ \\
\hline \multicolumn{5}{|l|}{ B. Health (All, aged 20 to 60 ) } \\
\hline $\begin{array}{l}\text { Self-reported health, } \\
\text { ordinal measure }\end{array}$ & $\begin{array}{l}0.502 * * * \\
(0.057)\end{array}$ & $\begin{array}{c}0.462 * * \\
(0.200)\end{array}$ & $\begin{array}{c}-0.018 * * \\
(0.008)\end{array}$ & $\begin{array}{c}-0.038 * * * \\
(0.002)\end{array}$ \\
\hline Good or very good health & $\begin{array}{c}0.128 * * * \\
(0.021)\end{array}$ & $\begin{array}{c}0.065 \\
(0.080)\end{array}$ & $\begin{array}{l}-0.002 \\
(0.003)\end{array}$ & $\begin{array}{c}-0.038 * * * \\
(0.002)\end{array}$ \\
\hline Bad or very bad health & $\begin{array}{c}-0.067 * * * \\
(0.015)\end{array}$ & $\begin{array}{c}-0.106^{* *} \\
(0.049)\end{array}$ & $\begin{array}{c}0.004 * * \\
(0.002)\end{array}$ & $\begin{array}{c}-0.038 * * * \\
(0.002)\end{array}$ \\
\hline Long-term health problem & $\begin{array}{c}-0.125^{* * *} \\
(0.029)\end{array}$ & $\begin{array}{l}-0.069 \\
(0.068)\end{array}$ & $\begin{array}{c}0.003 \\
(0.003)\end{array}$ & $\begin{array}{c}-0.038 * * * \\
(0.002)\end{array}$ \\
\hline \multicolumn{5}{|c|}{ C. Fertility (Females, aged 20 and over) } \\
\hline Age at having first child & $\begin{array}{c}3.086 * * * \\
(0.704)\end{array}$ & $\begin{array}{l}-0.818 \\
(3.343)\end{array}$ & $\begin{array}{c}0.027 \\
(0.111)\end{array}$ & $\begin{array}{c}-0.033 * * * \\
(0.005)\end{array}$ \\
\hline Teenage mother & $\begin{array}{c}-0.148 * * * \\
(0.041)\end{array}$ & $\begin{array}{c}-0.319 * * * \\
(0.113)\end{array}$ & $\begin{array}{c}0.016 * * * \\
(0.005)\end{array}$ & $\begin{array}{c}-0.051 * * * \\
(0.004)\end{array}$ \\
\hline Number of children & $\begin{array}{c}-0.551 * * * \\
(0.177)\end{array}$ & $\begin{array}{l}-0.821 \\
(0.584)\end{array}$ & $\begin{array}{c}0.035 \\
(0.025)\end{array}$ & $\begin{array}{c}-0.043 * * * \\
(0.005)\end{array}$ \\
\hline Child birthweight (kilogrammes) & $\begin{array}{l}-0.023 \\
(0.042)\end{array}$ & $\begin{array}{l}-0.016 \\
(0.207)\end{array}$ & $\begin{array}{c}0.001 \\
(0.011)\end{array}$ & $\begin{array}{c}-0.053 * * * \\
(0.002)\end{array}$ \\
\hline
\end{tabular}

Notes: $* * * p<.01, * * p<.05$, and $* p<.10$. Standard errors are clustered by country of birth. IV and OLS are the estimates of $\beta_{1}$ in equation (1) using IV and OLS estimators, respectively, where an indicator for speaking English "very well" is used as a measure of English skills. First-stage and reduced-form are the estimates of the coefficients on the interaction of age at arrival and linguistic distance from the origin country. Refer to Table 2 for sample sizes and controls included. The F-statistics on the excluded instrument in column 4 range from 43 to 460 .

Source: Authors' calculations based on the ONS Longitudinal Study. 